\title{
LA CIUDAD DE TOLUCA DURANTE \\ LA GUERRA Y LA CONSUMACIÓN DE LA INDEPENDENCIA
}

\author{
THE CITY OF TOLUCA DURING THE WAR \\ AND CONSUMMATION OF THE \\ INDEPENDENCE
}

\author{
María del Pilar Iracheta Cenecorta \\ El Colegio Mexiquense, A.C. \\ pirachet@cma.edu.mx
}

\begin{abstract}
We analyze the participation of Toluca during the war and consummation of the Independence, posing the question: How the society of a provincial city as Toluca undergone the uprising of members of the City Council of Mexico City in 1808 and the Civil War beginning in 1810, also calamities like famine, epidemies and economic exactions demanded by both sides? I intend to answer it taking the perspective of social history. Finally, I stand out the establishment of the first constitutional Town Hall, extinguished in 1814 and reestablished in 1820, which has since been the representative body of Toluca inhabitants.
\end{abstract}

Keywords: Independence, war, consummation, Town Hall, Toluca.

\section{Resumen}

Este artículo aborda la historia de Toluca durante la guerra y la consumación de la Independencia con base en la siguiente pregunta de investigación: ¿cómo experimentó la sociedad de una ciudad provincial como Toluca el movimiento de 1808, la guerra civil y los flagelos como el hambre, las epidemias y los pagos exigidos por los dos bandos contendientes? Para contestarla es utilizada la perspectiva de la historia social. Finalmente, destaca el establecimiento del primer ayuntamiento constitucional, extinguido en 1814 y restablecido en 1820, que se constituye como el organismo representativo de los toluqueños.

Palabras clave: Independencia, guerra, consumación, Ayuntamiento, Toluca. 


\section{Retrato de la ciudad de Toluca entre el ocaso del régimen virreinal y los albores del siglo XIX}

Toluca era una villa provincial novohispana, convertida en ciudad a finales de 1799 (si bien se le denominaba con dicha categoría desde el siglo XVII), cuyo título había sido otorgado por Cédula Real por el rey Carlos IV para excusar a la ciudad el pago de derechos "por su antigüedad y pobreza".2

En este núcleo urbano confluía un pequeño asentamiento hispano, gobernado por un corregidor, con población de españoles, criollos, mestizos y castas, así como barrios y pueblos en los que habitaban los indios, con su gobierno autóctono, representado por el gobernador o alcalde y el cabildo de indios (Beligand, 2017).
Desde tiempos prehispánicos, la cabecera matlatzinca de Toluca y el valle del mismo nombre se conformaron como sitios estratégicos para el abasto de la gran Tenochtitlan. Durante el virreinato, la ciudad de México fue la más favorecida: recibía trigo, maíz y otros productos provenientes de los alrededores del inmenso Valle de México - Michoacán, Guadalajara y Valle de Toluca-. A éste estaba integrado el Corregimiento de Toluca, cuyo centro era la villa española del mismo nombre (la antigua cabecera matlatzinca de Toluca). Hacia fines de 1810 contaba con 25 pueblos y ocho barrios -es decir, nuestro universo de estudio (mapa 1)-, aunque aclaro que los procesos y acontecimientos históricos abordados necesariamente abarcaron zonas más amplias.

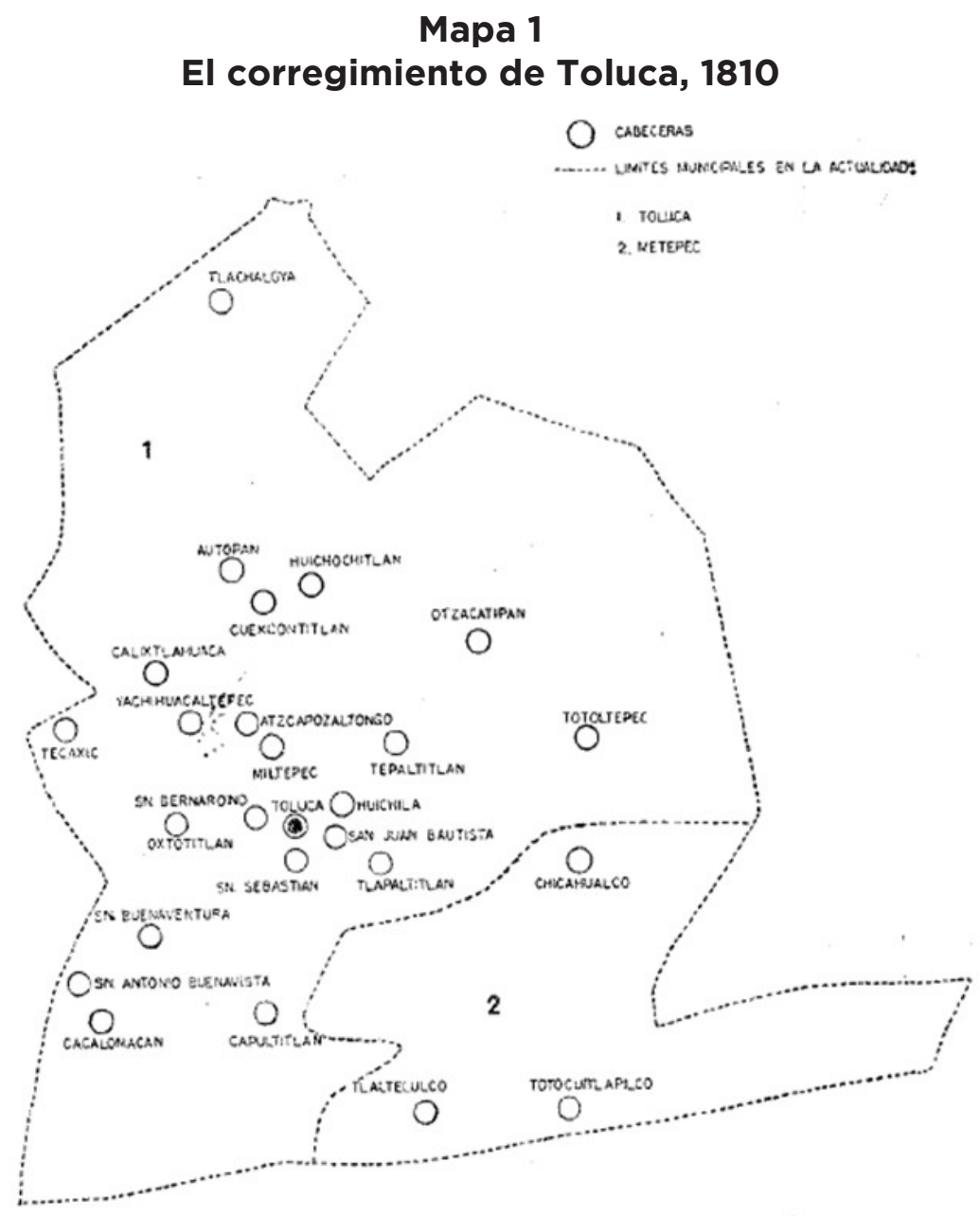

Pueblos del corregimiento de Toluca - 1810

Fuente: "Corregimiento de Toluca y elecciones de república en el siglo XVII" (Alanís Boyso, 1976). 
La villa de Toluca gozaba de una posición estratégica como un cruce de caminos hacia la ciudad de México, Michoacán, Morelos y Guerrero. El camino carretero de México a Toluca se construyó entre 1791 y 1795 con el objeto de posibilitar el abaratamiento de los costos y la disminución en el tiempo de transporte de los alimentos producidos no sólo en el Valle de Toluca, sino en Cuernavaca, la zona de Michoacán y Guadalajara, que abastecían a la capital (León García, 2002). En cuanto a la población, Mark Mairot (2013) hace notar que entre 1750 y 1800 -como en otras partes de la región central de Nueva España- la cantidad de españoles de Toluca se duplicó: el núcleo urbano contabilizó 5289 habitantes casi al final del siglo XVIII. La población indígena en los barrios y pueblos creció a una tasa comparable a la de la década de la guerra de Independencia, al parecer porque las personas buscaron refugio ante los peligros del campo.

En cuanto al perfil étnico, Bayardo y otros, basados en el Censo de 1791, afirman que Toluca tenía un total de 5155 habitantes (134 menos que los que consigna Mairot); de ellos, $3075-57 \%$ de la población censada- no tenían calidad étnica.
Además, la población indígena no fue censada; en este sentido, las cifras representan aproximadamente $10 \%$ de la población del Corregimiento de Toluca. De este modo, figuraban 1143 personas clasificadas como criollas, 344 mestizas y 212 castizas (Bayardo Rodríguez et al., 2018). En cuanto al perfil socioeconómico, los cuadros 1 y 2 dan cuenta de las actividades económicas de los toluqueños en 1791 por grupo social:

\section{Cuadro 1 Actividades de la población de Toluca, 1791}

\begin{tabular}{|c|c|c|}
\hline Actividades & Número & Porcentaje \\
\hline Agrícola & 83 & 10 \\
\hline Artesanal & 295 & 38 \\
\hline Comercio & 125 & 16 \\
\hline Servicios & 135 & 18 \\
\hline Profesiones & 30 & 4 \\
\hline Religión & 15 & 2 \\
\hline Ejército & 34 & 4 \\
\hline Gobierno & 43 & 6 \\
\hline Otros & 13 & 2 \\
\hline Total & 773 & 100 \\
\hline
\end{tabular}

Fuente: Bayardo Rodríguez et al., 2018: 70.

\section{Cuadro 2}

\section{Actividades de la población de Toluca por grupo social, 1791}

\begin{tabular}{|c|c|c|c|c|c|c|c|c|c|}
\hline $\begin{array}{c}\text { Sin es- } \\
\text { pecificar }\end{array}$ & 11 & 61 & 9 & 21 & 8 & 11 & 16 & 8 & 1 \\
$\begin{array}{c}\text { Criollo } \\
\text { Peninsu- } \\
\text { lar }\end{array}$ & 24 & 140 & 60 & 43 & 14 & 3 & 6 & 22 & 6 \\
\hline Castizo & 6 & 19 & 7 & 5 & 0 & 1 & 0 & 0 & 0 \\
\hline Indio & 0 & 0 & 0 & 1 & 0 & 0 & 0 & 0 & 0 \\
\hline Mestizo & 42 & 75 & 29 & 64 & 8 & 0 & 7 & 3 & 0 \\
\hline Negro & 0 & 0 & 0 & 0 & 0 & 0 & 0 & 0 & 1 \\
\hline Total & 83 & 295 & 125 & 135 & 30 & 15 & 34 & 43 & 13 \\
\hline
\end{tabular}

Fuente: Bayardo Rodríguez et al., 2018: 71.

El cuadro 2 muestra, en primer lugar, que el criollo fue el grupo étnico mayoritario y también tiene la más alta cantidad en todas las actividades. Con respecto a los sectores económicos, el artesanal representó 38\% (el más alto) de las actividades de la población. ${ }^{3}$ 
Llama la atención que el porcentaje del sector servicios esté por encima del agrícola, en el cual están los mestizos en primer lugar y luego los criollos.

A su vez, el comercio destaca como la actividad principal de la élite, aunque no fue exclusivo de ésta; de la población adulta 125 personas eran comerciantes, de un total de 773 personas de las que se tiene información sobre su ocupación, porque el total eran 1208 adultos de sexo masculino. Entre las personas dedicadas al comercio predominaban los criollos y la mayoría de los peninsulares.

Es importante resaltar que aunque los mestizos representaron apenas $5 \%$ de la población censada, tuvieron importante participación en la agricultura, artesanía y comercio. Finalmente, señalo la importancia de los peninsulares en el sector comercio pero también en el gubernamental, quienes acaparaban los puestos burocráticos más importantes: corregidor, administrador de aduanas, alcabalas, de carne; los criollos también figuraron en la actividad burocrática, pero ocupando puestos de menor categoría (Bayardo Rodríguez et al., 2018).

\section{Los tres pilares del orden novohispano toluqueño en los albores del siglo XIX}

A principios del siglo XIX, Toluca todavía era regida por los tres pilares garantes del orden colonial: el eclesiástico, las élites política y económica y el ejército, los cuales presentaron una división interna entre sus filas tras el advenimiento del torbellino revolucionario. Desde el siglo XVI Toluca se encontraba bajo la jurisdicción del Marquesado del Valle, lo cual impidió a los pobladores españoles contar con un cabildo propio que actuara como mecanismo de representación colectiva entre los vecinos y la Corona.

Aparte de la Diputación de Toluca -que veremos más adelante-, como explica Karen Mejía Torres (2020), entre las formas de gobierno, gestión y cohesión, el régimen eclesiástico dio identidad e integración de Toluca a la Monarquía, propiciando la participación política vecinal. De este modo, en- tre la segunda mitad del siglo XVII y hasta finales del siglo XVIII, se constituyó un régimen eclesiástico corporativo que fungió como correa de transmisión y reproducción del orden monárquico y factor de consolidación de la villa de Toluca como ciudad; también fungió como un instrumento de gobierno y participación política y de incidencia de los grupos sociales toluqueños en varias materias, como las obras públicas o las epidemias. El funcionamiento de este régimen corporativo eclesiástico entrelazó prácticas religiosas con las políticas de los grupos involucrados en la búsqueda del bien común y en la conservación de la república.

Mejía argumenta que la llegada de nuevas órdenes a la villa -carmelitas, juaninos y mercedarios- generó una dinámica corporativa que minó la duradera preponderancia de los franciscanos en Toluca y sus pueblos, propiciando relaciones conflictivas por la defensa de las órdenes religiosas; sin embargo, no mermó el prestigio moral y social de los franciscanos entre la población.

La última década del siglo XVIII marcó una mayor tensión entre las corporaciones y feligreses, sumada a los deseos reformistas de las autoridades. Pero, como sucedió desde el siglo XVII, propició una gran capacidad de adaptación y negociación entre las órdenes, una armonía sustentada en el resguardo de un orden que fuera funcional en los ámbitos local y monárquico (Mejía Torres, 2020), el cual sufriría una sacudida con el vendaval revolucionario.

Adelantada la primera mitad del siglo XVIII, Carlos III, a partir de la caída de La Habana y Manila en poder de los ingleses, planeó una reorganización completa del ejército. Se concibió el proyecto de levantar fuerzas armadas en América, cuya actividad debía responder a la política imperial centralizadora (Guedea Rincón Gallardo, 2002).

La idea era mantener la paz interna en Nueva España y tener los elementos para defenderse de los crecientes ataques enemigos. De este modo, llegaron varios militares peninsulares, entre ellos Francisco de Villalba y Angulo, a quien en 1764 se le ordenó la creación de un ejército. Se formaron 
varios cuerpos, entre ellos los regimientos provinciales, como el de Toluca, establecido en 1765. Luego fue suprimido y restablecido entre 1794 y 1796, permaneciendo hasta principios del periodo post independista. ${ }^{4}$

El reclutamiento y la organización de las milicias fue una tarea complicada, pues pasado un tiempo algunas se hallaron incompletas, sin disciplina y, a veces, con poca ética; al principio no fueron aptas para el servicio (Guedea Rincón Gallardo, 2002). A reserva de realizar una investigación profunda sobre el tema del Regimiento Provincial de Infantería de Toluca, éste presentó algunas de estas fallas. ${ }^{5}$

En cuanto a la élite, Toluca era un núcleo urbano pequeño, dependiente de la ciudad de México, y centro distribuidor e importador de bienes, en el cual, desde el siglo XVI y hasta el XVIII, aparte de la religiosa y militar, se conformó una élite política y económica que fortaleció su posición como representante del vecindario, integrada por funcionarios, comerciantes, hacendados, con fortunas inferiores a las de la élite capitalina, de quien copiaban su modelo de vida.

La población hispana de Toluca era la más influyente y rica, dedicada a la producción, procesamiento y comercialización de alimentos para la ciudad de México y otras ciudades menores y pueblos como Valladolid, Puebla, Zacatecas, Celaya y Pungarabato (León García, 2002).

Mark Mairot (2013) argumenta que, entre 1777 y 1834, en Toluca se reveló la presencia de una élite terrateniente y comercial más claramente cohesionada e interconectada, ligada por un conjunto de relaciones familiares, sociales y de negocios. Este grupo -ligado social y económicamente a la ciudad de México- vivía en Toluca y tenía lazos sociales y culturales con ella.

Por otra parte, el poder de la élite también fue manifiesto en la diversidad de personas que colaboraron en la manutención del culto y el sostenimiento de corporaciones religiosas (Mejía Torres, 2020). En cuanto al estatus social, entre los donadores destacaron los de alto rango social que antepusieron a su nombre de pila el prefijo "don" o "doña".
Además, algunos también usaban los títulos de bachiller, capitán, fraile y licenciado (Mejía Torres, 2020).

Bayardo Rodríguez y otros cruzaron esta variable con la de ocupación; plantean que los peninsulares y criollos -denominados "don"- dominaban la escena política y económica de la villa (Bayardo Rodríguez et al., 2018). Ahora bien, en Toluca, las élites criolla y peninsular, compuestas en su mayoría por hacendados y comerciantes, formaron parte de la llamada Diputación, un organismo con un Síndico del común y seis diputados (había dos diputados del comercio), la cual surgió en el último tercio del siglo XVIII. Esta corporación se constituyó como salvaguarda de los privilegios de la ciudad. Las elecciones de diputado y síndico se realizaban en sesión de cabildo ante la presencia de labradores y comerciantes, vecinos y principales. Las deliberaciones eran examinadas y aprobadas por el gobernador del Marquesado del Valle de Oaxaca y el virrey (Mejía Torres, 2020). La Diputación respondía a problemáticas del vecindario, aunque éste no siempre tenía voz.

En este sentido, los comerciantes locales eran perjudicados por el monopolio de comercio ejercido por funcionarios del Marquesado (Von Wobeser, 2018: 198). La diputación revisaba asuntos del ámbito militar: los padrones y los sorteos pertenecientes al Regimiento Provincial de Toluca; también organizaba el acceso al arriendo de alcabalas (Mejía Torres, 2020).

A principios del siglo XIX, las dos últimas diputaciones (1804-1806 y 1806-1810) se involucraron en la realización de obras públicas; por esta razón, la Diputación podría considerarse como un antecedente del ayuntamiento toluqueño. Dos diputados destacaron en 1804 y 1806: el coronel Nicolás Gutiérrez ${ }^{6}$ y el licenciado Francisco Gutiérrez Rubín de Celis, ${ }^{7}$ personajes omnipresentes -especialmente el primero- en las esferas política, militar, económica y social de Toluca antes, durante y después la guerra y un trecho del periodo posterior a la consumación de la Independencia. 
Don Nicolás Gutiérrez -que figuró como síndico de la Diputación de Toluca de 1804junto con los diputados, el alguacil mayor de la villa de Toluca, don Joseph Macario de Zúñiga, y el propio virrey -el arzobispo José de Lizana y Beaumont- cambiaron la imagen sucia y desordenada impuesta en parte por los ganaderos, ya que a finales del siglo XVIII existió una pugna entre los pobladores de las actividades derivadas de la ganadería contra los mercaderes. Así, los criadores de cerdo fueron enviados a las orillas de la villa (Mairot, 2013). En 1805 se realizaron varias obras públicas en el centro de la plaza y calles aledañas: una fuente pública y su cañería; dos pilas más, conocidas como la del Moro y la Mulita; también lavaderos; nivelación, empedrado y embanquetado de la calle San Juan, desde la plaza hasta la puerta de la calle que salía a la ciudad de México; el encortinado de la caja del río; la construcción de dos o tres puentes y la reconstrucción de las casas reales y cárcel públicas (Arriaga Rivera, 2017).

Toluca cerró la primera década del siglo XIX con un moderado avance urbano abanderado por la Diputación, integrada por una parte de la élite económica empresarial pujante, que resolvía algunos de los asuntos públicos de la ciudad, pero con los tres pilares del orden divididos y una sociedad desigual que sufrió abusos políticos y agravios fiscales cada vez más opresivos. En efecto, los criollos estaban inconformes con el control político que ejercían los peninsulares, así como su posicionamiento en la cúspide de la pirámide social y el acaparamiento de los mejores puestos públicos. Los campesinos, artesanos y trabajadores de servicios vivían con sueldos bajos y una vida precaria. Abundaban en la ciudad de Toluca los vagos, muchos de ellos artesanos sin trabajo, fuera de la protección de los gremios y bajo la mira punitiva del Estado.

También pululaban en Toluca muchos forasteros y jornaleros desempleados. En 1793 el corregidor Pedro de Larrea sugirió contratar a vagos y jornaleros para el nuevo camino Toluca-México; fueron aceptados los jornaleros pero no los vagos, "por el males- tar que causaría su vigilancia", 8 como si fueran delincuentes y no trabajadores desempleados. Asimismo, según el censo de 1791, una de cada cuatro familias no tenía domicilio físico, pues realizaba cambios continuos de vivienda; no era raro el ocultamiento de las familias para no pagar contribuciones o evadir el servicio en las milicias (Bayardo Rodríguez et al., 2018).

Los indígenas eran el grupo poblacional más grande; sufrieron largo tiempo agravios de varios tipos: abuso de autoridad por parte de los mandos locales españoles e indios, pago de diversas contribuciones y tributo, a veces de manera duplicada, así como la solicitud de los repartimientos de trabajo, cuando ya habían sido abolidos; ${ }^{9}$ el comercio ilícito de la producción indígena, el pago obligatorio de nueve "donativos graciosos" (entre 1781 y 1810) exigidos por la Corona, debido a los gastos provocados por las guerras emprendidas por España durante los siglos XVII y XVIII. ${ }^{10}$

En cuanto al ejército, un agravio importante fue que los dirigentes de los cuerpos milicianos eran directamente de origen español y nombrados por funcionarios en España, desplazando con ello a los criollos, a quienes se les negaban puestos, ascensos, pensiones, etcétera. ${ }^{11}$ Tampoco los militares estuvieron exentos del pago de los donativos y préstamos, cuya pesada carga suscitó la queja del comerciante criollo Ignacio García Sáenz, que fue capitán del Regimiento Provincial de Infantería de Toluca. ${ }^{12}$ Ahora bien, los fueros y privilegios militares se extendieron a las milicias provinciales a partir de 1767, lo que atrajo a las filas castrenses a mestizos, indios libres y afrodescendientes, fenómeno propio de América. Sin embargo, aquellos grupos pagaban tributo, ${ }^{13}$ aun estando en el regimiento; a partir de las Reformas Borbónicas aumentó la presión de las autoridades por el cobro del tributo. Ya avanzado el siglo XVIII, la exención tributaria se extendió ampliamente: el gobierno coIonial la otorgó provincia por provincia, tras haber observado y sopesado los méritos en cada caso (Castañeda García, 2014). En este contexto, atribuyendo presumiblemente el 
privilegio de no pagar el tributo por adscribirse a las milicias, en 1779 los integrantes del Regimiento Provincial de Infantería de Toluca, entre los que muy probablemente había mestizos y mulatos, pidieron que sus padres no continuaran pagando tributo. ${ }^{14}$ En suma, las cargas exigidas a los militares con poca motivación y falta de profesionalismo dieron como resultado que varios soldados del Regimiento desertaran ${ }^{15}$ y otros más se unieran a los rebeldes por considerar justa su causa. ${ }^{16}$

El bajo clero, criollo en su gran mayoría, experimentaba descontento por tener cerrado el acceso a la jerarquía del clero coIonial, principalmente ibérica, cuyos miembros constituían prácticamente la totalidad de los prelados novohispanos. No resultó extraño que, a inicios de la guerra, una buena parte del clero criollo siguiera a la insurgencia y otra permaneciera fiel al gobierno virreinal (Yurrieta Valdés, 2014: 24). ${ }^{17}$ Según Juan Ortiz Escamilla (2002: 210), en el Valle de Toluca la rebelión del Ilamado "proletariado clerical" pudo originarse debido al desempleo y al excesivo número de curas y vicarios existentes, suscitándose luchas por los curatos y vicarías. De este modo, algunos frailes franciscanos toluqueños nombrados coroneles por Miguel Hidalgo, como Pedro Orcillés -organizador de guerrillas en Coatepec, Huitzila, Huejutla, Tenango y Xocotitlán- (Santos Villarreal, 2010) y fray Antonio Gómez, recibieron los curatos de Tejupilco y Zacualpan, respectivamente.

No obstante, hubo frailes comprometidos con los insurgentes. Eric Van Young (en Beltrán Silva, 2018) destaca la importante participación de religiosos insurgentes en el centro de México. En particular indica que Toluca tuvo el mayor porcentaje de sacerdotes y religiosos rebeldes. Menciona que desde los inicios de la insurrección los frailes franciscanos del convento de Toluca se inclinaron a la causa rebelde: los padres Rafael Mañón y Pedro Flores, del convento de San Juan de Dios de Toluca, como miembros del clero participaron con disimulo, pero de forma efectiva en favor de la insurrección. Entre los que abiertamente actuaron en favor de los sublevados señala a Policarpo Be- rra, ${ }^{18}$ quien mantuvo trato directo con Ignacio López Rayón. Éste, contó además con la ayuda de correligionarios eclesiásticos que le facilitaron víveres, refugio, información, secrecía y todo tipo de ayuda.

El padre Collado, de Toluca, ofreció entrenamiento militar a sus reclutas y daba cobijo a los rebeldes fugitivos (Van Young, en Beltrán Silva, 2018: 93-94). Los frailes Joaquín Omaña y otro de apellido Olmedo participaron en la conspiración toluqueña de 1810; asimismo, fray Francisco Gómez, párroco del convento de San Francisco, dio sepultura a los muertos y fusilados de la batalla del Calvario. ${ }^{19}$ El padre José Manuel Izquierdo, nacido en Sultepec, inicialmente estuvo bajo las órdenes del brigadier Mariano Ortiz, sobrino del padre Miguel Hidalgo. Después militó en las filas del generalísimo José María Morelos y también de Leonardo Bravo. En 1811 era ya coronel y participó de manera destacada en la batalla de Tenango (septiembre de 1811), así como en los sitios de Toluca y Sultepec. Agustín de Iturbide lo atrajo a sus filas, por lo que Izquierdo firmó el Plan de Iguala y participó, junto con el coronel trigarante Vicente Filisola, en una decisiva Batalla contra las tropas del gobierno en la hacienda "La Huerta" (Zinacantepec) el 19 de junio de 1821 (Santos Villarreal, 2010).

\section{Toluca arrastrada al vendaval independentista}

La invasión napoleónica de España con la abdicación de Carlos IV y la ascensión al trono de Fernando VII, ambos presos en Bayona, hicieron estallar una crisis política en la ciudad de México, protagonizada por el virrey José de Iturrigaray y el Ayuntamiento de la Ciudad de México. Durante los 100 días que transcurrieron entre el 8 de junio y el 16 de septiembre de 1808 fue depuesto -por un grupo de españoles- el virrey y encarcelados los miembros del cuerpo edilicio, como Francisco Primo de Verdad y Ramos y el fraile peruano Melchor de Talamantes. En el lugar de Iturrigaray fue nombrado un militar, Pedro de Garibay, quien en mayo de 1809 fue sustituido por el arzobispo de Méxi- 
co, Francisco Xavier de Lizana y Beaumont. Miguel Ángel Fernández Delgado (2012) explica que el proyecto del ayuntamiento en 1808 fue autonomista y no secesionista, ya que el deseo de la independencia se generalizó algunos años después. El periodo 18081810 todavía estuvo marcado por la fidelidad hacia la Corona española.

Para el ayuntamiento de la ciudad de México y sus adeptos, en su mayoría criollos, la Nueva España tenía en 1808 la categoría de un reino incorporado por conquista a la Corona de Castilla, semejante en todo a los reinos peninsulares y, por lo tanto, con derecho a establecer una junta para encargarse de su gobierno en forma interina.

En contraste, para la Audiencia de México y los españoles que la apoyaban, la Nueva España era considerada como una simple colonia subordinada a la metrópoli española, carente de voz y de voto. El abortado movimiento del ayuntamiento de la ciudad de México en favor de la Independencia, iniciado en 1808, impactó en algunos grupos sociales de la ciudad de Toluca. Personas anónimas publicaron una convocatoria para alistar a hombres diestros en el manejo de las armas, listos para un eventual alzamiento. Supongo que bien pudieron ser criollos, mestizos e indios que conspirarían en 1810 para derrocar a los peninsulares de Toluca. El gobierno virreinal formó un expediente para averiguar el origen y la autoría de tal convocatoria. ${ }^{20}$ Una parte importante de la élite toluqueña se alarmó por estos hechos y solicitó al virrey que no sustituyera al corregidor interino de la jurisdicción -y síndico de la Diputación-, el coronel realista Nicolás Gutiérrez, ${ }^{21}$ feroz persecutor de los insurgentes.

El pueblo español fue leal al sistema monárquico y confiaba en el espejismo, repetido por siglos, de que un nuevo monarca -en este caso el cautivo Fernando VII- arreglaría los problemas: la intensa crisis generada en España por la invasión napoleónica (Mínguez Cornelles, 2007: 247). Era también la esperanza en América. Entre 1808 y 1809, en las ciudades de los virreinatos novohispanos se dieron las Juras de Fernando VII. ${ }^{22}$
En septiembre de 1809 el corregidor Nicolás Gutiérrez convocó a la Diputación 18061809 para organizar la Jura en Toluca. ${ }^{23}$ Con este motivo, salió a la luz la pugna política entre Nicolás Gutiérrez, anterior síndico del común de la ciudad y primer diputado en 1804, y su sucesor para el periodo 18061809, el licenciado Francisco Gutiérrez Rubín de Celis, nombrado por la Diputación alférez real para la organización de la Jura. Éste propuso un impuesto a la población para costear una ceremonia de gran lucimiento. Nicolás Gutiérrez propuso en cambio una Jura normal; ${ }^{24}$ argumentó que "la natural pobreza que siempre se ha experimentado en este país" había aumentado por la carestía de trigo, maíz, géneros y "otros efectos".

En efecto, la Nueva España, en particular la Intendencia de México, sufrió una crisis agrícola y carestía de granos entre 1808 y 1810. En agosto de 1809 -advirtió Gutiérrezno hubo maíz ni pan, cuyo precio subió a 12 pesos. La única cosecha de maíz existente iba a agotarse. Aún más, el corregidor sugirió no invitar a la Jura a los soldados del Regimiento Provincial de Infantería de Toluca ni a sus familias, cuya manutención ya pesaba sobre la ciudad, evitando así "la devastación" de la cosecha de 1809 para el año siguiente. Sin embargo, Gutiérrez recaudó los donativos y préstamos impuestos ese año por el virrey. ${ }^{25}$

El corregidor expresó la fundada preocupación -compartida por las autoridades civiles y eclesiásticas de la Nueva España- sobre un posible alzamiento popular en contra del control del precio y las existencias de los granos. Gutiérrez argumentó que, según el gobierno, las Juras sólo se llevarían a cabo en poblaciones que tuvieran un ayuntamiento, lo cual no era el caso de Toluca. Añadió que la complicada situación política en España ante la invasión napoleónica, la prisión del rey Fernando VII y su impacto en la Nueva España "tienen lánguidos los corazones de todos estos infelices vasallos".

Los vecinos, quizá presionados por el propio corregidor, firmaron un documento en el que rendían obediencia a Fernando VII, 
pero se opusieron al gravoso proyecto de Gutiérrez Rubín de Celis, por lo que solicitaron a dicho corregidor omitir los gastos. De cualquier manera, se ordenó a Gutiérrez celebrar la Jura los días 8, 9 y 10 de enero de $1810,{ }^{26}$ aunque el estallido de la guerra lo impidió; finalmente se llevó a cabo hasta junio de 1814, presidida por el Ayuntamiento Constitucional de Toluca, con misas, Te Deum, cohetes, salvas, repiques, procesión militar, comida y baile público. ${ }^{27}$

De vuelta a 1809, mientras discurría el litigio sobre la Jura fernandina, un anónimo alertó a las autoridades sobre "especies sediciosas [escritas en pasquines] vertidas en Toluca". Los pasquines se mandaron a archivar, agregándolos a otros escritos de la misma especie. ${ }^{28}$ Los acontecimientos se desencadenaron. En septiembre de 1810 se supo de una conspiración insurgente en Toluca, integrada presumiblemente por varios de los alzados en 1809.

Esta conspiración estaba probablemente vinculada -como las de la ciudad de México, Querétaro, Celaya, San Luis Potosí, Zacatecas, Veracruz y Cuernavaca- a la Junta Secreta, instaurada en San Miguel el Grande (ahora de Allende) en 1808, organizada por el capitán Ignacio Allende. ${ }^{29}$ En efecto, el avance insurgente hacia la ciudad de Toluca se apoyó de emisarios para insurreccionar las poblaciones en busca de la sedición e infidencia en contra del régimen virreinal (Beltrán Silva, 2018: 83). En Toluca, los denominados "jinetes mensajeros" Manuel Vargas y Mariano Espinosa estuvieron vinculados precisamente al capitán Ignacio Allende. Una mayoría de criollos formó la dirigencia de la conspiración toluqueña: en primer lugar, el herrero Joaquín Canseco, un futuro líder insurgente, y sus dos hijos, Francisco y José María. Joaquín posteriormente se uniría a José María Oviedo, nombrado comandante militar por la Suprema Junta de Zitácuaro.

Entre los toluqueños adheridos a la conspiración hubo hacendados como Mariano Garduño; los comerciantes José Suárez del Castillo, Bernardino Vega, Cristóbal Cruz y José Mariano Espinosa; los frailes francisca- nos Rafael Olmedo y el presbítero Omaña, así como un boticario, un cafetero, los licenciados Ruperto Álvarez, José María Olascoaga y José María Azoñoz, antiguo asesor letrado de la Intendencia de México (Pérez Hernández, 2017: 224).

Éste y el hacendado Mariano Garduño serían después integrantes del ayuntamiento toluqueño de 1813; Mariano Farfán, Joaquín Nicolás de Llera, contador de la aduana de Toluca, Marcelo Díaz, Ángel Arias, Gerardo Duén, Felipe Pereyra, Mariano Sánchez, Mariano Rivas, Domingo Reyes, José Zarco y Juan Reyes, Jorge León, Sixto. Ricardo Ramírez, José Lucas Guadarrama. También un fiscal llamado Pastor, integrante de la República de Indios de Toluca, ofreció reclutar unos mil indios de los barrios y pueblos circundantes.

Los conspiradores organizaron un plan de asalto contra los gachupines: avanzar por cada uno de los puntos cardinales de la ciudad a fin de acorralarlos hasta la plaza principal en el centro de Toluca "para amarrarlos y llevárselos al capitán Ignacio Allende" (MTV, 2012). ${ }^{30}$ Pero fueron traicionados por un infiltrado: José Suárez, ${ }^{31}$ alguacil mayor de la ciudad de Toluca, bajo el mando del corregidor de Toluca Nicolás Gutiérrez, quien ejerció dicho cargo de 1808 a 1810.32 El 9 de octubre de 1810 fueron encarcelados el presbítero Omaña, el abogado Álvarez, don Mariano Farfán, el contador de la aduana don Joaquín Nicolás de la Llera, don José María Olascoaga, los jinetes Manuel Vargas y Mariano Espinosa; antes habían sido capturados Ángel Arias, Gerardo Duén, Bernardo Vega ${ }^{33}$ y otros más, los cuales fueron enviados a la cárcel por el alguacil mayor. ${ }^{34}$ Su traslado a la ciudad de México causó el escandaloso alboroto de un grupo de personas en la Calle del Maíz (hoy andador Constitución en el centro).

Fueron enjuiciados en Toluca por el abogado Ángel María de Castro por orden del corregidor Nicolás Gutiérrez el 25 de octubre. Los cabecillas y algunos seguidores fueron encarcelados en la ciudad de México por órdenes del virrey Francisco Javier Venegas. ${ }^{35}$ Permanecieron presos Antonio Or- 
dóñez, el barbero Marcelino, Bernardo Vega y Mariano Garduño (García Luna y Victoria Moreno, 2013). Una proclama había sido colocada el 8 de octubre de 1810 en la puerta de la capilla de la Santa Veracruz y en el cementerio de Toluca, que decía: "Toluqueños y criollos, tanto de razón como indios, no creas las proclamas que los infames gachupines nos hacen, libraos de la nación europea y seguir la secta de nosotros los criollos, que es lo más conveniente y os promete felicidad. Compatriotas, luchen por la libertad, no sean cobardes, que más viable es la cárcel que ser esclavo de los gachupines" (MTV, 2012).

A pesar de la represión, el 15 de octubre de 1810 todavía circularon en los callejones y calles toluqueñas unos volantes donde se leía: "Viva la independencia y mueran los que a ella se opongan", escritos en papel de estraza, para convocar a unirse a la lucha por la libertad. ${ }^{36}$

\section{La batalla del Monte de las Cruces, 30 de octubre de 1810}

La aprehensión de los conspiradores el 1 de octubre se produjo sólo días antes de la llegada a Toluca -el 28 de octubre de 1810- de don Miguel Hidalgo y los capitanes Ignacio Allende, Mariano Abasolo, Mariano Matamoros y su ejército insurgente, que era esperado en las inmediaciones de Ixtlahuaca por las fuerzas del Regimiento Provincial de Infantería de Toluca y algunas otras fuerzas regionales, pero se retiraron al cabo por la desigualdad en el número de efectivos. En efecto, los insurgentes eran unos 80,000. Un día antes, en la noche del 27 de octubre, Torcuato Trujillo, quien había sido desplazado a Toluca por el virrey Francisco Xavier Venegas para enfrentar a Hidalgo y sus tropas, tuvo que salir con sus oficiales, dragones y los realistas a acantonarse en Lerma, al no ser suficientes para enfrentar a los insurgentes, no sin antes cerrar con fosos y trincheras la calzada que de Toluca conduce a esta villa; de esta manera interceptaron el camino carretero a la ciudad de México (Villalpando César, 2002).
Las tropas de Trujillo eran seguidas en mayor parte por españoles y criollos de la élite residente en Toluca, aterrados por la inminente llegada de las huestes insurgentes. Trujillo previó saqueos y se llevó el numerario de las cajas del Rey y el de la colecturía del diezmo.

También se llevó a 40 prisioneros, que eran vecinos honrados, sospechosos de simpatizar con Hidalgo; seguramente varios de ellos formaron parte de la conspiración insurgente. Estas aprehensiones fueron el inicio de la persecución contra los civiles toluqueños (Iracheta Cenecorta y Martínez García, 2002). No obstante, el virrey Venegas reunió una fuerte y selecta división de 2000 hombres al mando de Trujillo, para resistir el avance de los insurgentes y evitar a toda costa que entraran al Valle de México. Componían esta fuerza los cuerpos de infantería Regimiento de Tres Villas y la caballería del Regimiento de Dragones de España, sin artillería; los subalternos de Trujillo eran el mayor José Mendivil, Antonio Bringas y el entonces alférez del Regimiento Provincial de Valladolid, Agustín de Iturbide (Villalpando César, 2002), quien por su actuación fue ascendido a capitán del Batallón Provincial de Tula.

Luego de pernoctar dos días en Toluca, el ejército insurgente se dirigió hacia el Monte de las Cruces, donde se libró la famosa batalla el 30 de octubre de 1810. Los realistas fueron derrotados por los más de 80000 insurgentes, quienes consiguieron gran parte del armamento español y estuvieron a un paso de tomar la ciudad de México; sin embargo, por motivos desconocidos, Hidalgo decidió no entrar a la capital y se retiró al Bajío, donde el 7 de noviembre Félix María Calleja, entonces brigadier de la división de caballería, infligió la primera derrota insurgente en la batalla de Aculco, hecho que distanció a Hidalgo de Allende.

Así, los jefes insurgentes tomaron rutas distintas: el primero marchó a Valladolid y el segundo a Guanajuato (Villalpando César, 2002). La derrota realista implicó un quiebre en la estrategia para combatir la insurgencia. 


\section{El control político-territorial-militar}

Con el establecimiento de la Constitución de Cádiz, que tuvo vigencia en Nueva España desde septiembre de 1812, el virrey Francisco Xavier Venegas fue nombrado primer Jefe Superior Político y Capitán General de la Nueva España. Sin embargo, debido a que Venegas fue ineficaz para acabar con los rebeldes, lo sucedió Félix María Calleja, quien fungió como el segundo Jefe Superior Político y Capitán General de la Nueva España desde el 4 de marzo de 1813; éste instrumentó un control político-territorial-militar que también se aplicó en Toluca y otras zonas cercanas. El Reglamento político-militar emitido por Calleja -vigente entre 1811 y 1813- descentralizó el control de las Provincias a través de la creación de 10 Comandancias Militares en varias ciudades novohispanas.

Se dieron concesiones a las Comandancias Generales, convirtiéndolas en jurisdicciones semiautónomas y autónomas, que devinieron verdaderas "satrapías militares" (Moreno Gutiérrez, 2014: 22). También se dio la formación de cuerpos armados locales voluntarios llamados "Patriotas distinguidos defensores de Fernando VII" y "Fieles realistas defensores de Fernando VII", Ios cuales, fusionados, formaron las compañías de milicias patrióticas, cuerpos de defensa del régimen virreinal, que combinaron los grupos armados oficiales y de autodefensa: hombres de los pueblos o trabajadores de las fincas, involucrados en la defensa contra los insurgentes.

De paso, aligeraron a la hacienda colonial, porque la gente pudiente sustentó a las compañías que actuaban en las demarcaciones cercanas. Más adelante, como se verá, en Toluca -y en general en las poblaciones novohispanas- las tropas realistas dejarían totalmente la seguridad a los grupos civiles (Moreno Gutiérrez, 2014: 21-22).

El proceso de control en Toluca comenzó con el envío a la ciudad del batallón ligero de Cuautitlán, Ilamado "Ligero de México", al mando del teniente coronel Juan Sánchez, instalado en Toluca a mediados de no- viembre de 1810. Como comandante militar (nombrado aun antes de la creación de la comandancia en Toluca), además de dirigir las fuerzas militares, estableció un tribunal de excepción: la Junta de Seguridad y Buen Orden de la ciudad de Toluca, inspirada en la de la ciudad de México instaurada en 1809 - cuando había signos muy claros de intranquilidad en Nueva España- por el arzobispo-virrey Francisco de Lizana y Beaumont para castigar delitos políticos, especialmente los que atentaran contra la seguridad del Reino.

Después de la revolución del padre Miguel Hidalgo, la Junta amplió sus facultades para perseguir y castigar actitudes favorables a la rebelión de manera directa o indirecta, actuando contra toda infidencia o rebeldía al poder, a quien se debía obediencia (Ibarra Romero, 1995: 101). La Junta de Toluca fue autorizada por el virrey y constituida el 22 de noviembre de 1810; funcionó hasta 1821.

La Junta castigaría o indultaría a los "novatores, sediciosos y adheridos al partido de los insurgentes" que se presentaran voluntariamente y procesar a los que se aprehendieran y resultaran delincuentes. Recobraría los bienes usurpados; restablecería el buen orden, paz y tranquilidad de toda la jurisdicción y proporcionaría defensa ante cualquier intento de invasión.

El corregidor realista Nicolás Gutiérrez fungió como presidente y como vocales el licenciado Antonio Careaga y Carlos del Pozo; Prudencio Gutiérrez, vecino y comerciante de la ciudad, fue nombrado secretario de la junta. ${ }^{37}$

El teniente coronel Sánchez y su batallón abandonaron Toluca el 9 de enero de 1811. En ese año, Toluca fue una de las 10 comandancias militares, compuestas por fuerzas regulares (el Regimiento Provincial de Infantería de Toluca) para combatir a la insurgencia. El 9 de enero de 1811 se nombró al Brigadier Rosendo Porlier -traído de Guadalajara- como Comandante Militar de Toluca, en lugar de Juan Sánchez (Beltrán Silva, 2018). 


\section{Toluca y su valle bajo dos fuegos}

Desde antes y después del paso de don Miguel Hidalgo, las incursiones de los realistas e insurgentes afectaron tanto a los españoles y criollos pudientes de Toluca como a los mestizos e indígenas de los barrios y pueblos aledaños acusados de apoyar a la insurgencia.

Cuando Torcuato Trujillo, coronel realista, fue destacado en Toluca, al entrar a los pueblos indígenas toluqueños ordenó a los soldados que cortaran las orejas o fueran pasadas por la espada las personas que contestaran el "¿Quién vive?" con la frase "Nuestra Señora de Guadalupe". En ocasiones, los residentes españoles de Toluca solicitaban a las autoridades realistas aprehender o fusilar a personas acusadas de insurgentes y que, en realidad, nada tenían que ver con la insurrección (Iracheta Cenecorta y Martínez García, 2002). El virrey Venegas impuso las milicias realistas, llamadas "guerrillas volantes", compuestas por forajidos españoles, que reprimieron manifestaciones pro insurgentes en el Valle de Toluca. Pero su violencia extrema obligó al virrey a sustituirla por una división militar a cargo de Juan Bautista de la Torre, capitán veterano del regimiento de Tres Villas, y Ventura Mora, capitán del regimiento Fijo de México (Beltrán Silva, 2018).

A principios de 1811, como producto de la acción de estas divisiones, hubo matanzas de indígenas en haciendas y pueblos como Cacalomacán, Oxtotitlán y San Antonio Buenavista.

A Tlacotepec, como a otros pueblos, Ilegó, el 8 de enero de 1811, una cordillera o carta convocatoria firmada por el capitán insurgente José Simón Rubín de Celis, en nombre de Miguel Hidalgo e Ignacio Allende, pidiendo apoyo para la lucha insurgente. El escribano Rufino Sevario y el alcalde de Tlacotepec, Alexo de la Cruz, la firmaron; fueron encarcelados y sometidos a juicio, acusados de insurgentes. ${ }^{38}$

\section{La Suprema Junta Americana y el asedio a Toluca, 1811-1812}

Con el fusilamiento de Hidalgo, Allende y otros jefes insurgentes, entre junio y julio de 1811, el movimiento insurgente fue comandado por el cura de Carácuaro, don José María Morelos y Pavón, vinculado con un grupo de intelectuales que intentaban dar significado e institucionalidad a la rebelión americana, quienes conformaron la Suprema Junta Americana el 19 de agosto de 1811 y cuyos líderes fueron el licenciado Ignacio Rayón -minero y vecino de Tlalpujahua y exsecretario de don Miguel Hidalgo-, José María Liceaga y José Sixto Verduzco. Dicho organismo se consolidó como el centro coordinador de los rebeldes (López Ponce, 2017: 96).

Los grupos insurgentes apostados en el norte de la ciudad de México obstaculizaban las comunicaciones y el comercio con los centros mineros del Bajío con el objetivo de colapsar al gobierno virreinal. La intercepción de los caminos y las comunicaciones y el tráfico de mercancías a través del decomiso fue la base para el aprovisionamiento de los insurgentes y su permanencia en el conflicto armado. Una vez ocupado un territorio, se realizaba el asalto a convoyes y los bienes que transportaba. Ello constituyó el principal factor de abastecimiento de las tropas insurgentes en la región de Toluca. Asimismo, la Suprema Junta Nacional Americana organizó de mejor manera a los caudillos y actividades de la insurrección. Se consolidó el territorio del norte como foco insurgente, cuya influencia se extendió hacia el sur, ejerciendo fuerte presión a la capital virreinal (Beltrán Silva, 2018: 44). Las tropas realistas debían cruzar Toluca para combatir a las de Rayón y perseguir a los grupos comandados por el general José María Morelos, quienes iban hacia el sur, llegando hasta el litoral del Pacífico.

José María Oviedo, jefe de una guerrilla mazahua-otomí y ex compañero de batallas de Benedicto López, fue nombrado por la Suprema Junta Americana brigadier para la región de Tenango del Valle. Después de 
derrotar en Zitácuaro al general realista Miguel de Emparán, Oviedo recibió órdenes de la Suprema Junta para defender Tenango, con el objeto de detener los avances del comandante realista Rosendo Porlier, quien se había apoderado de Tenancingo y esperaba que cayera también Tenango para retener a Toluca como plaza del gobierno virreinal. De paso, intentaba destruir las partidas insurgentes que actuaban desde los desfiladeros de Zitácuaro hacia las Ilanuras de la intendencia de México. El comandante realista atacó Tenango los días 21 y 22 de septiembre de 1811. Por su parte, Oviedo, junto con los coroneles Epitacio Sánchez, Atilano García y Manuel Correa, Juan Agustín Cruz Manjarrez, Juan Albarrán y otros dos apellidados Montes de Oca y Marín, se posesionaron del cerro de Tenango. Al frente de unos seis mil hombres -la mayoría de ellos mazahuas y otomíes-, Oviedo tuvo el apoyo de ocho cañones de pequeño calibre. Lo asistió Joaquín Canseco, proveniente de Tenancingo, con indios de 20 pueblos. Fue destacada la actuación de los indígenas en la batalla, quienes desde las alturas lanzaron enormes peñascos contra los soldados realistas. Al atardecer, Porlier, prácticamente derrotado, suspendió el ataque y retrocedió a Toluca, su centro de operaciones (López Ponce, 2017). A su paso, arrasó con el pueblo de San Juan Evangelista, en las inmediaciones de Toluca (Landavazo, 2008: 32). Los insurgentes apostaron por el triunfo en Toluca para cerrar el paso a los realistas en su avance hacia Zitácuaro, donde se aposentaba la Suprema Junta Americana.

\section{La batalla de El Calvario}

El brigadier José María Oviedo había logrado sujetar a la obediencia de la Suprema Junta Nacional, con residencia en Zitácuaro, a los grupos armados de Juan Agustín Cruz, Juan Albarrán, Mariano Montes de Oca, José Víctor Rosales, Mariano Garduño, José Carmonal y varios frailes. Con el conocimiento y anuencia de José María Morelos, quien estaba en Chilapa (López Ponce, 2017: 99), Oviedo avanzó a Toluca seguido por un enorme contingente de indígenas y grupos diversos. La noche del 7 de octubre los insurgentes llegaron a la ciudad y tomaron posesión de los cerros de Zopilocalco, San Miguel Apinahuizo, Cóporo, Coatepec, San Luis Obispo, San Juan Evangelista, Huitzila y Calvario. Oviedo distribuyó a sus fuerzas y algunos vecinos se sumaron a la defensa en siete sitios estratégicos. Intentarían poner un cerco a los realistas y desatar un ataque envolvente que dividiera y debilitara sus defensas, para luego inutilizar o capturar sus piezas de artillería y obligarlos a gastar sus municiones. Pero el brigadier Porlier instrumentó un plan de ataque -enviado el 28 de octubre siguiente al virrey Francisco Xavier Venegas- consistente en levantar cortaduras y parapetos en los principales puntos de riesgo de ataque, especialmente los que conectaban con calles céntricas. Se trataba de evitar a toda costa el avance insurgente a través de fortalezas inexpugnables.

Como la ofensiva vendría de diferentes direcciones, se instalaron cortaduras al oriente, poniente, norte y sur (mapa 2).

\section{Mapa 2 \\ Plan de defensa realista en la batalla de El Calvario, 19 de octubre de 1811}

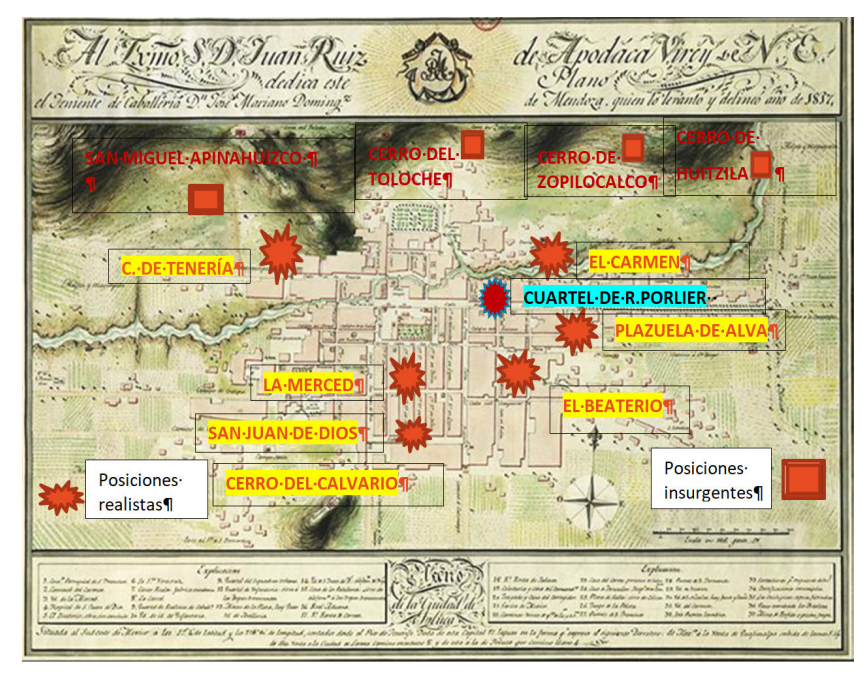

Fuente: Plano de la ciudad de Toluca levantado de orden superior por el teniente agregado al Cuerpo de Ingenieros, José Mariano Domínguez de Mendoza (Barry Lawrence Ruderman Antique Maps Inc., 1817). 
En cuatro días de lucha (del 14 al 18 de octubre), los españoles defendieron como pudieron sus posiciones iniciales, pero los atacantes incursionaban por diferentes puntos y causaban grandes estragos en casas, el cementerio, la Plaza Mayor y otros sitios. Los realistas tuvieron que retroceder y concentrarse en la defensa del cerro de El Calvario, por donde la fuerza enemiga trataba de entrar al centro de la ciudad. Españoles, civiles y eclesiásticos exigieron a Porlier poner fin al sitio. Acorralado, con escaso poder de ataque y pocas municiones, solicitó refuerzos urgentes al virrey Venegas y le manifestó la posible pérdida de la plaza si no llegaban las tropas. Al quinto día (18 de octubre), Porlier se presentó en el cerro de El Calvario y distribuyó su infantería en guerrillas, como una táctica contrainsurgente, con la caballería a derecha e izquierda y ambas protegidas por la artillería. Ese mismo día llegó el capitán Joaquín María de la Cueva, seguido de una columna de 200 infantes, 160 dragones y un par de cañones de grueso calibre; entraron a Toluca por Lerma. La feroz acometida del capitán de la Cueva hizo estragos en las filas insurgentes, prácticamente exhaustas tras cinco días de intensos combates, de manera que la defensa no duró mucho. El ejército de Oviedo fue casi desbaratado y huyó hacia Tenancingo y Tecualoya (hoy Villa Guerrero). Según Porlier, tuvo dos bajas y 23 heridos en su división, así como un muerto y ocho heridos en la comandada por De la Cueva (Peñaloza García, 2011; Iracheta y Martínez García, 2002). Terminada la batalla, el 19 de octubre tuvo lugar un hecho atroz. Una crónica realizada por integrantes del Ayuntamiento de Toluca en 1840 sobre la guerra de Independencia relata que las guerrillas realistas bajaron los cañones y otros artefactos; con los dragones se repartieron por los pueblos inmediatos a El Calvario, donde saquearon a todos los vecinos, la mayor parte indígenas. Guerrilleros y dragones sustrajeron de sus casas a más de 200 hombres inocentes como prisioneros de guerra; Porlier hizo que en la Plaza Mayor fusilaran en la tarde a 67 de esos prisioneros, el resto escapó por una casuali- dad (Iracheta Cenecorta y Martínez García, 2002). El número de fusilados en la Plaza de Toluca ronda los 63, contabilizados en la partida de defunción del párroco toluqueño fray Francisco Gómez, emitida el 19 de octubre de 1811; el fraile agregó la cantidad de 282 muertos en el campo de batalla. ${ }^{39}$ Por la duración y el encarnizamiento de la lucha, así como los muertos y fusilados, considero que ésta fue una de las batallas más sangrientas de la guerra de Independencia. Para rematar, la represión realista se extendió a pueblos circunvecinos: La Asunción Malacatepec, San Mateo, Amanalco, Temascaltepec y los alrededores de la hacienda La Gavia. También en Jocotitlán, donde se registró un levantamiento de los pobladores que fue aplastado por las tropas realistas al mando de Juan Bautista de la Torre. Otro pueblo reprimido fue Tlacotepec; en un informe, fray Francisco Gómez, cura ministro de la ciudad de Toluca, comentó al padre provisor y capitular que el 9 de junio de 1811 tenía noticia - sin confirmar- de que las tropas realistas salieron de Toluca a "demoler, desolar y quemar" el Pueblo de Tlacotepec perteneciente a la doctrina de Toluca, con la sospecha de que en el pueblo se escondían varios insurgentes. ${ }^{40}$

\section{Toluca y las campañas de Ignacio Rayón}

Después de la batalla de El Calvario, en 1812 Rayón hizo un nuevo intento para tomar Toluca. El caudillo salió de Sultepec, donde se aposentaba la Suprema Junta Americana, expulsada de Zitácuaro en junio de 1812. Rayón avanzó a las inmediaciones de Toluca. Durante su estancia en Zinacantepec firmó los Elementos Constitucionales, considerados por algunos historiadores como la primera constitución mexicana. Instaló su campamento en la hacienda "La Huerta". Inició el ataque el 10 de abril. Rosendo Porlier era el jefe realista de la plaza de Toluca, quien presentó una férrea resistencia a los insurgentes. Rayón acorraló a Porlier y a sus tropas en el convento de San Francisco, en el corazón de la ciudad. No obstante, 
a un paso de la victoria, Rayón decidió la retirada, al escasear el parque; pero el sitio de las tropas a la ciudad se mantuvo. Rayón tomó el camino a Tlacotepec e incendió la hacienda "La Garcesa", propiedad del coronel Nicolás Gutiérrez, corregidor de Toluca. Al enterarse de la situación y del sitio en que se mantenía a Toluca, el virrey envió 1500 hombres al mando de Castillo Bustamante para reforzar la tropa y la artillería de Porlier. Rayón impidió que Porlier fuera auxiliado y el 19 de mayo se trasladó a Lerma para evitar el ingreso de las tropas enviadas por Venegas. Con suficientes hombres y armamento, Castillo Bustamante fue a liberar Lerma. Los insurgentes rechazaron a los realistas para luego abandonar la plaza; se reunieron y fortificaron en Tenango, al lado de Ignacio Rayón. De nuevo, Castillo Bustamante los enfrentó. El 6 de junio arrebató a los insurgentes el cerro y el pueblo (Beltrán Silva, 2018: 96-97). ${ }^{41}$

\section{La ciudad realista}

Luego del repliegue de los insurgentes en Tenango, a mediados de 1812 Lerma y Zinacantepec fueron arrebatados a los insurgentes, junto con el camino a la ciudad de México. A finales de mayo de 1812, Toluca y sus contornos quedaron libres de insurgentes en un radio de treinta leguas (Beltrán Silva, 2018). Pero la presencia de Ignacio Rayón y sus aliados en el Valle de Toluca era una amenaza persistente contra el régimen coIonial y en especial para la ciudad de Toluca. Por ello, el ejército realista instaló destacamentos en los sitios recién recuperados, vitales para la administración virreinal. A partir de ese momento, Toluca se convirtió en un importante baluarte realista. En mayo de 1812 tenía instalados diversos cuerpos militares: Urbano de Toluca de Marina, Artillería, Regimientos Provinciales de Puebla y México, Fijo de México, Dragones de Caballería de España, México y Querétaro y la División de José Barrachina. En total sumaban 609 individuos de infantería y 329 de caballería (Beltrán Silva, 2018). Estos cuerpos armados estaban a cargo del brigadier Rosendo Por- lier, el capitán Benito Salas, el subteniente Luis Puyade y el teniente coronel José María Cobián. Toluca contó, además, con un "Real Parque de Artillería", donde se almacenaba el armamento de fuego y seguramente contaba con taller de elaboración y restauración de armas, muchas de ellas tomadas de los insurgentes para su reparación y reutilización. Toluca funcionó como un centro o base militar: una buena cantidad de los destacamentos acantonados en la ciudad realizó expediciones a diferentes puntos de la región. Desde Toluca fue planeado el desalojo de la fortificación de Tenango; la excursión a Sultepec para desalojar a la Suprema Junta Americana instalada en Zitácuaro, entre otras acciones militares. Las tropas acantonadas para el resguardo de la ciudad -militares y artillería- estaban distribuidos en calles, callejones y plazas (Beltrán Silva, 2018).

\section{El Ayuntamiento Constitucional de Toluca}

La Constitución de Cádiz fue promulgada y jurada en la Nueva España el 30 de septiembre de 1812. El virrey Calleja no simpatizaba con las elecciones para ayuntamientos ordenadas por la Constitución, pero dispuso la Jura para evitar perder el poder sobre los nuevos organismos implantados por aquéIla: las diputaciones provinciales y las jefaturas políticas, así como sobre la Hacienda Pública (Ortiz Escamilla, 2000: 46). En Toluca, Nicolás Gutiérrez encabezó la Jura de la Constitución junto con los administradores de Rentas, los oficiales del Escuadrón Urbano de Caballería de Toluca, el alguacil mayor de la República de Indios, el juez eclesiástico y los sacerdotes de las órdenes existentes en Toluca, así como los vecinos de distinción (Gazeta del Gobierno de México, 1812: 1215-1218, 1223-1226). En este periodo de máximo control militar realista nació el primer ayuntamiento constitucional de Toluca, gracias al decreto de Fernando VII del 23 de mayo de 1812, que ordenaba formar los ayuntamientos previstos en la Constitución de Cádiz de 1812. Con la instauración 
del cuerpo edilicio toluqueño en 1812 se dio el paso trascendental de un gobierno señorial a uno constitucional, pues fueron abolidos el juzgado privativo y los privilegios del marquesado del Valle, que en 1809 había sufrido una cuarta y última confiscación por la Corona como represalia contra el XIII marqués por haber aceptado la embajada de España en Francia, a instancias del impuesto rey de España, José Bonaparte, hermano de Napoleón. Asimismo, fueron suprimidas sus facultades gubernativas y jurisdiccionales, por decreto del Soberano y Supremo Consejo de la Regencia del 22 de agosto de 1811 (Pérez Hernández, 2017: 80).

El Señorío fue recuperado en 1816 y llegó íntegro hasta 1821, aunque solamente para recuperar el derecho de cobrar las rentas de las empresas y los censos de su estado, porque, como se comentó, ya se habían abolido los tributos y señoríos jurisdiccionales (García Martínez, 1969).

Si bien la Diputación de Toluca podría considerarse un organismo antecesor del ayuntamiento, el rasgo común entre ambas instituciones fue la repetición de algunos de sus integrantes y la presencia conspicua de la élite de hacendados y comerciantes, a los que se añadiría un reducido grupo de individuos con profesiones liberales. La diferencia entre ambas fue que los miembros del ayuntamiento fueron electos por la población mediante voto indirecto, tomando en sus riendas la administración de los asuntos públicos y las necesidades del vecindario toluqueño.

\section{La epidemia de tifo}

A la complejidad de la guerra se unió la epidemia de tifo, iniciada en el sitio de Cuautla en febrero de $1812 .^{42}$ De ahí se extendió a toda la Intendencia de México por los movimientos del ejército realista. Según María del Carmen Sánchez Uriarte (1997: 44-50), y considerando que la subdelegación de Toluca -ciudad, barrios y pueblos- contaba con aproximadamente 15,554 habitantes, la tasa de mortalidad ascendió a $30.50 \%$, siendo el tercer lugar entre las 18 subdelegaciones de la Intendencia de México, después de Pachuca (32.4\%) y Zumpango (40.13\%).

La infección por tifo se transmite, sobre todo, a través de los piquetes de piojos que se han alimentado de un enfermo contagioso. Los síntomas iniciales son catarro fuerte, calentura, escalofríos, dolor de cabeza, dolor en los músculos y en el pecho; sarpullido en las arcas y luego en el cuerpo, después en los brazos y piernas. En la subdelegación de Toluca los más afectados fueron los adultos de todos los grupos sociales que correspondieron a las tres regiones o rutas -otomíes del Norte, no indios, incluidos españoles, castizos, mulatos y mestizos que habitaban en la Cabecera (Toluca) y mexicanos otomíes repartidos alrededor de la cabecera y en el Sur-. La epidemia comenzó a incrementarse en mayo y se prolongó hasta octubre. Los párvulos fueron afectados mortalmente casi a la par que los adultos, en especial los de los tres pueblos otomíes en el norte: San Pablo Autopan, San Andrés Cuexcontitlán y San Cristóbal Huichochitlán; en 1813 desapareció un tercio de su población. En suma, en 1813 murieron por tifo casi 500 adultos no indios, sumando españoles, castizos, mestizos y mulatos. De los no indios, en 1813 murió uno de cada 10 (Javier López, 2017).

Como parte de sus atribuciones, el Ayuntamiento Constitucional de Toluca ejerció sus primeras labores de salubridad para enfrentar la epidemia. Con el apoyo de los capitulares y los vecinos, estableció un hospital "a beneficio de las mujeres, pobres y forasteros que no tenían a dónde curarse de las fiebres epidémicas y por tirarse enfermos en las calles contagiaban al vecindario". ${ }^{43}$

\section{El ayuntamiento y el financiamiento de los cuerpos de defensa}

Durante la guerra, las fuerzas militares constituyeron una fuerte inversión, la cual implicó nuevas cargas fiscales para los nacientes ayuntamientos y para la población (Pacheco Chávez, 2004: 48). Entre 1813 y 1814 se produjo un periodo de crisis económica en Nueva España. En este contexto, el virrey 
Calleja, quien había sido nombrado virrey en 1814, con atribuciones y jurisdicción territorial más amplia, implantó una nueva contribución directa de guerra, recaudada por los ayuntamientos y que iba destinada al ejército, así como el establecimiento de las Juntas Locales de Hacienda en cada cabecera de partido (Pacheco Chávez, 2004: 48, 50, 58).

Como en otros lugares de la Nueva España, en la comandancia militar de Toluca se levantaron las Compañías de Patriotas, cuya cabeza fue el coronel Lorenzo de Angulo y Guardamino, nombrado por el virrey Calleja comandante de las armas de Toluca el 11 de mayo de 1813; también presidió entre 1813 y 1814 la Junta de Seguridad y Buen Orden contra infidentes toluqueños. Angulo, nacido en el País Vasco, fue un personaje multifacético: comerciante, miembro del consulado de México, regidor del Ayuntamiento de la Ciudad de México, hacendado, minero, coronel del Regimiento Provincial de Infantería de Toluca y teniente coronel del regimiento de Infantería provincial de Tlaxcala e integrante de la Junta Superior de Sanidad, instalada por la Diputación Provincial de México; en 1806 fue nombrado caballero de la Orden Militar de Montesa. ${ }^{44}$ Como Nicolás Gutiérrez y Francisco Gutiérrez Rubín de Celis, Angulo tuvo un importante -aunque no duradero- peso político, económico y militar en el Valle de Toluca. Calleja planeaba sostener a las Compañías de Patriotas con las aportaciones de los hacendados, con 100 plazas en cada localidad, que evitaran el reingreso de grupos insurgentes en el Valle de Toluca; sin embargo, los dueños de las fincas no aceptaron las cuotas por considerarlas muy altas.

Por orden del virrey, Angulo y Nicolás Gutiérrez, jefe del Escuadrón de Caballería Urbana de Toluca, formarían un fondo o contribución para la subsistencia de ese cuerpo con 150 plazas, pero las comunicaciones de los comandantes generales y provinciales entre sí y con el virrey mostraron la difícil coordinación militar y de abasto. Los comandantes militares u otros funcionarios procuraban consolidar el control de su jurisdicción antes que socorrer a la colin- dante con hombres, dinero, armas, bestias o pertrechos (Moreno Gutiérrez, 2018: 112). A mediados de 1813, Angulo denunció la falta de recursos para el sostenimiento de la Compañía de Patriotas (Beltrán Silva, 2018). Al no conseguir las cuotas necesarias de los hacendados, Angulo solicitó al cuerpo edilicio toluqueño un préstamo de 30,000 pesos para alimentar a las compañías militares. El cabildo se negó, por no contar con presupuesto, pues había dado dinero que no le fue reintegrado.

En su informe sobre Toluca al virrey Calleja, Angulo expuso que de los 220 hombres de la tropa, 99 se ocupaban del resguardo de la ciudad vistiendo uniformes viejos. El Escuadrón Urbano de Caballería Urbana de Toluca sólo contaba con 42 hombres listos para el servicio; el resto, 110 hombres, carecían de caballos, armas e instrucción. La recién creada Compañía de Patriotas carecía de toda instrucción, "encontrándose en estado miserable": contaba con 83 plazas, pero sólo 65 poseían armas, porque no fueron surtidas las restantes, como tampoco los caballos. El 5 de marzo de 1814 el ayuntamiento comunicó a Angulo que la hacienda municipal contaba con muy pocos arbitrios para apoyar al Cuerpo de Patriotas. ${ }^{45}$ Las contribuciones directas seguían manteniendo al Escuadrón Urbano, que había recibido 80,000 pesos anuales para fortificaciones, reparaciones y otros gastos, pero la tropa debía reunir 14,469 pesos para remonta, vestuario y armamento, por lo que solicitó aportaciones "a todo el que tuviera posibilidad, llegando a valerse del secuestro y enajenación de bienes para obligar a la gente a contribuir" (Beltrán Silva, 2018: 100).

El panorama expuesto por el ayuntamiento era desolador: la miseria del vecindario, la falta de dinero, el atraso en la agricultura, la falta de animales para trabajar la tierra, la escasez de víveres, el comercio arruinado, la escasa industria, las afectaciones por la epidemia de tifo, las pocas contribuciones y las poblaciones desiertas como Totocuitlapilco, San Bartolomé, San Mateo Oxtotitlán, San Pedro Totoltepec y Santa Ana. En abril de 1814 la presión de Angulo sobre el 
ayuntamiento suscitó una aguda pugna entre ambos. Angulo informó al virrey Félix Calleja la negativa del cabildo de facilitarle 100,000 pesos para realizar una expedición al suroeste de la región de Toluca. El dinero era para la manutención de la Compañía de Patriotas bajo el mando del coronel Manuel de la Concha.

El presidente del cuerpo municipal, el licenciado Antonio Careaga, volvió a negar los recursos a la tropa de Angulo, pues no había fondos para el Escuadrón Urbano de Caballería de Toluca. Los hacendados tampoco podían sufragar los gastos porque, al deber otras contribuciones, sus fincas quedaron en manos del gobierno para no ser perseguidos por éste. Cabe comentar que estas fricciones parecieron originarse por el hecho de que las Juntas de Vecinos y la de Hacienda, dispuestas por Calleja, no se habían conformado todavía. Mientras esto sucedía, el virrey dispuso que el ayuntamiento toluqueño sostuviera los Cuerpos de Patriotas. El cuerpo edilicio expresó que Lorenzo de Angulo y Guardamino sostenía una pugna contra el cabildo, el cual sí había aportado recursos para la expedición de dicho militar; en 1815 éste zanjó su conflicto con los ediles al salir obligadamente de Toluca. El ayuntamiento se ocupó de la formación de la guardia de la ciudad y propuso a Francisco Aranda, ex integrante del Regimiento Provincial de Infantería de Toluca, y a Juan Bascones, un ciudadano toluqueño distinguido, como oficiales para comandar la Compañía de Patriotas de la ciudad (Beltrán Silva, 2018.). En agosto de 1814 el Ayuntamiento Constitucional de Toluca, presidido por el licenciado Antonio Careaga, ${ }^{46}$ propuso al virrey Félix María Calleja ceder al gobierno virreinal el Escuadrón Urbano de Caballería de Toluca, mantenido por el cabildo, para que dispusiera de él tanto en la ciudad como en su jurisdicción. La corporación entregó poco más de 12,000 pesos que aportaban anualmente las haciendas del partido de Toluca para el sostenimiento del Escuadrón, (Beltrán Silva, 2018), el cual, todavía en 1816 -cuando se establecieron las Comandancias militares de Querétaro, Tu- lancingo y Toluca que sustituyeron a los gobiernos políticos distritales (Pérez Hernández, 2017: 22)- era dirigido por el nombrado comandante de las armas de Toluca, Nicolás Gutiérrez, que contaba con 282 efectivos. Hasta 1817 algunos hacendados se negaron a dar cuotas, por lo que el juez subdelegado de Toluca, Francisco Gutiérrez Rubín de Celis, libró el cobro del adeudo y embargo de bienes. El coronel Manuel de la Concha quitó finalmente al ayuntamiento el sostenimiento del Escuadrón Urbano, el cual fue sustituido por compañías realistas, con menos plazas activas (Beltrán Silva, 2018).

\section{El control político-militar del ayuntamiento}

El reglamento político militar expedido por Félix María Calleja en 1813 ordenó que el gobierno militar y civil de las subdelegaciones debía concentrarse en una sola persona, cuyo nombramiento recaería en los comandantes militares de cada región y en el intendente en turno. Esta decisión implicó que la mayor parte de subdelegados fueran militares en activo (Pérez Hernández, 2017: 22). En el caso de Toluca, el coronel Lorenzo de Angulo y Guardamino recibió la orden expresa de Calleja de presidir los acuerdos del ayuntamiento de 1813. En 1814 se impuso al nuevo ayuntamiento el coronel Nicolás Gutiérrez, jefe político de la jurisdicción de Toluca y recién nombrado nuevo comandante de las armas, en sustitución de Angulo. El ayuntamiento, amenazado por Calleja, acató el nombramiento, no sin antes protestar, porque éste transgredía el mandato de la Constitución de Cádiz de 1812, que separaba el mando político del militar, violentado por Gutiérrez al presidir los acuerdos edilicios. ${ }^{47}$

El cuerpo edilicio toluqueño se disolvió en diciembre de 1814, pues, liberado de su cautiverio, el rey Fernando VII derogó la Constitución de Cádiz y declaró nulos todos los actos de las Cortes gaditanas y de las juntas. En su lugar quedó de nuevo la Diputación de Toluca, a cargo de la administración de los asuntos públicos. El ayuntamiento nombró a los miembros: como cabeza figu- 
ró el juez subdelegado de Toluca, el licenciado Francisco Gutiérrez Rubín de Celis, como diputado más antiguo; el licenciado Juan Manuel Azorrey, antiguo secretario del ayuntamiento; don Francisco Luis Serrano, antiguo regidor; don Miguel Montes de Oca, antiguo regidor, y don Justo Valdés, antiguo síndico, que debían ser relevados al año siguiente del nombramiento. ${ }^{48}$ En 1815, Gutiérrez Rubín de Celis juró, en compañía de toda la Diputación de Toluca, el decreto de Calleja en contra de la libertad de imprenta para censurar la prensa de los insurgentes (Gazeta del Gobierno de México, 1815: 796798).

\section{La restauración de la Constitución de Cádiz y el restablecimiento del ayuntamiento (1820)}

Desde 1819, varios oficiales españoles se adhirieron al Plan para restaurar la Constitución de Cádiz. El 1 de enero el coronel Rafael del Riego proclamó la necesidad de regresar al orden constitucional. El rey Fernando VII, libre del cautiverio de Napoleón en 1814 y proclamado monarca absoluto, había derogado la Constitución Gaditana. Pero en 1820 la presión popular y militar lo obligó a aceptarla. La juró en marzo de 1820; a su vez, el virrey de Nueva España hizo lo propio el 3 de mayo de 1820. Este acontecimiento señala el inicio del periodo constitucional de Fernando VII, Ilamado el "trienio liberal" en España (Carmona Dávila, 2021). En Toluca se juró en junio de aquel año. Andrés Quintana Roo, quien entonces residía en Toluca con su esposa Leona Vicario, escribió para la magna ocasión una composición alegórica. Un fragmento reza:

\footnotetext{
Desaparece la oscura Tiranía,

Incierta y triste por los aires vaga,

Hasta que á las regiones del oriente,

Su antiguo asilo, el torpe paso avanza.

El ancho océano su ámbito espacioso,

En justo obsequio de la nueva grata

Reduce á breve trecho, y facilita

Estorbos que pudiera hallar la fama.
}

Viene pues, por el México anunciando

Que ya la Libertad reina en España,

Cuyo duro dominio ó Tiranía

Cambiará presto en amistosa alianza. ${ }^{49}$

Restablecido el orden constitucional, fueron restaurados los ayuntamientos constitucionales. Como lo explica Sánchez Montiel (2009), gracias a ellos se reforzaron varios conceptos liberales introducidos desde los primeros ayuntamientos de 1812, como el régimen representativo, la participación política de la ciudadanía, la igualdad jurídica de las localidades y el carácter electivo de la mayor parte de los cargos públicos, elementos de la cultura política local que facilitaron una mayor intervención de los pueblos. Este proceso no fue inmediato, se desarrolló entre el primer y segundo periodos de vigencia de la carta gaditana, con resultados variables en cada lugar en función de sus condiciones particulares. Los ayuntamientos debieron enfrentar a algunas instituciones, personajes, estructuras y prácticas del antiguo régimen que intervenían en la administración de las instituciones locales (Sánchez Montiel, 2009: 38). Al respecto, en 1820 el coronel y comandante de las armas de Toluca, Nicolás Gutiérrez, figuró de nueva cuenta como presidente del cuerpo edilicio y "alcalde de primer voto". Explico esa permanencia porque Gutiérrez defendió los intereses de las élites española y criolla, garantizando el orden que éstas exigían; sin embargo, su arraigo en Toluca -a la que gobernó como corregidor- y las obras realizadas en Toluca como integrante de la Diputación, en ocasiones sufragadas con sus propios recursos, le ganaron aprecio (Romero Quiroz, 1973: 160).

En el ámbito económico, el ayuntamiento no contó con total independencia. Existieron dos organismos superiores a los ayuntamientos que tenían injerencia en la hacienda municipal: la Diputación Provincial, que podía legislar en materia fiscal, y los jefes políticos, que debían aprobar lo sancionado por las diputaciones provinciales y hacer que se ejecutaran los acuerdos (Pacheco Chávez, 2004: 41-42). Además, ni la constitución 
gaditana ni los decretos de las Cortes de Cádiz especificaron los propios y arbitrios que debían manejar los ayuntamientos. Sólo en 1822 la Diputación Provincial de México concibió algunos arbitrios que serían manejados por los cuerpos edilicios, pero el Congreso General nunca le autorizó el plan de propios y arbitrios que había formulado. Por ello, entre 1814 y 1820-1821 -y en los años siguientes-, los ayuntamientos toluqueños emprendieron obras públicas; pero ya desde esa época, y en adelante, la corporación municipal tuvo que apoyarse en gran parte en la cooperación monetaria de los vecinos.

Otro ámbito que estorbaba al ayuntamiento fue el militar. Como lo explica Guzmán Pérez (2014), la reimplantación de la Constitución liberal en 1820 repercutió directamente en la estructura militar que se había arraigado en los pueblos. Las milicias urbanas, que se habían formado con base en el Reglamento Político Militar del virrey Calleja en 1811, debían desaparecer, debido a que la Carta Magna no permitía la existencia de juntas locales de arbitrios ni contribuciones forzosas para sostener a las milicias. Los ayuntamientos constitucionales creados en pueblos y provincias terminaron con las contribuciones y desarticularon las compañías urbanas y rurales al segarse su principal fuente de manutención. En el caso de Toluca, los capitulares acordaron el levantamiento de la Milicia Nacional en Toluca, que sustituiría a dicho escuadrón. ${ }^{50}$ Sin embargo, esta medida no fue inmediata: en marzo, Casimiro Lejarazu, sustituto de $\mathrm{Ni}$ colás Gutiérrez, dispuso que el cuerpo edilicio cobrara a los ayuntamientos foráneos una contribución para el Escuadrón Urbano de Caballería de Toluca y se dispusiera de ese dinero para sostener a otras compañías. Asimismo, a principios de junio de 1821, los toluqueños, entre ellos los indios, mantenían a los militares fieles a España. En este sentido, los indios de los barrios toluqueños de San Sebastián, San Juan Bautista y Huitzila solicitaron que no se les cobrara ni que los obligaran a solventar el pago atrasado de la contribución personal para los Escuadrones Urbanos y Realistas. Los capitulares no sabían qué hacer: la hacienda municipal no contaba con fondos y los vecinos de la ciudad no contribuirían con el faltante por estar "recargados de pensiones". Asimismo, los vecinos se quejaron porque sus casas eran habitadas por los soldados, que incomodaban a sus familias; por esta razón solicitaron que los militares fueran asignados al cuartel del Callejón de El Carmen, a un costado de la iglesia del mismo nombre..$^{51}$

Como lo explica José Luis Romero (1984: 173), en los albores del siglo XIX las ciudades latinoamericanas experimentaron por lo general una continuidad en el trazo de su estructura urbana, pero sufrieron cambios en su estructura social. Las clases dirigentes de las ciudades formaron muchas veces parte de la élite criolla que triunfaría en las luchas independentistas. El ayuntamiento toluqueño de 1820 y 1821 fue compuesto precisamente por miembros de la élite criolla, pero también por profesionistas liberales, quienes, a lo largo del tiempo, fueron conformando al cuerpo edilicio como la institución representativa de los toluqueños, justificando, defendiendo y ampliando las prácticas de gobierno frente a otros actores bajo el fundamento de la administración de los asuntos públicos de la ciudad, sus barrios y pueblos.

En este sentido, las cortes generales y extraordinarias de Cádiz decretaron el 23 de junio de 1813 que los ayuntamientos constitucionales estarían a cargo de la "policía urbana", definida como "la que se refiere al cuidado de la vía pública en general: limpieza, higiene, salubridad y ornato de los pueblos, encomendada de manera directa a los ayuntamientos y a los alcaldes"; posteriormente fueron añadidos rubros como la educación primaria, la beneficencia, la distribución del agua potable, cobro de impuestos, supervisión de mercados, etcétera (RAE, 1976: 311; De Pagés, 1932: 478-479). De este modo, entre 1820 y 1821 el cuerpo edilicio se ocupó de diversos asuntos: emitió el Bando Municipal -vigente en 1821-, que reglamentó la higiene y la salubridad-mediante la creación de la Junta de Sanidad-, el orden urbano y hasta las costumbres; levantó un 
censo de la ciudad, barrios y pueblos, tarea dificultosa porque los indios no estaban en sus pueblos sino en las haciendas, levantando las cosechas; se erigió como patrono de una escuela particular para niños; construyó nuevas fuentes y cañerías para el abasto de agua, así como alcantarillas, y reparó la cárcel, apoyado en la renta de unas casas pertenecientes al extinto Marquesado del Valle. ${ }^{52}$

\section{La consumación de la Independencia y su celebración en Toluca}

La proclamación del Plan de Iguala el 24 de febrero de 1821, redactado por el coronel Agustín de Iturbide, dio carácter institucional al movimiento trigarante. La originalidad del Plan consistió en proponer una Constitución acorde con la historia, las creencias y las costumbres de los habitantes de la América Septentrional, y fue explícito respecto a la composición multirracial de la América mexicana, hecho recibido con beneplácito por el coronel Vicente Guerrero y sus huestes (Del Arenal Fenochio, en Guzmán Pérez, 2014). Desde el 10 de enero de 1821 Iturbide logró un acuerdo con Guerrero, quien le hizo jurar que pugnaría por la separación definitiva de España y a cambio sus hombres mantendrían sus posiciones, respetando a sus mandos (Guzmán Pérez, 2014). El éxito de Iturbide tuvo que ver con la antigua estructura militar creada desde los primeros años de la insurrección con el plan de Calleja a cuyo mando estuvo Agustín. Esto le facilitó la construcción de una red de contactos con oficiales de diferente graduación, ubicados en distintos territorios de la Nueva España, muchos de los cuales se adhirieron a la causa. No fueron pocos los soldados y oficiales que abandonaron la causa de un rey para apoyar la Independencia y obtener un nuevo grado militar, un salario alto y mayores grados oficiales (Guzmán Pérez, 2014). Este fenómeno se presentó en Toluca. ${ }^{53}$ Como lo señala Guzmán Pérez (2014), un factor importante del triunfo del movimiento trigarante fue la negociación por encima de la violencia, con acuerdos políticos entre los jefes de las milicias y los emisarios de Iturbide -entre ellos los subdelegados, justicias y ayuntamientos de las provinciaspara evitar los enfrentamientos militares, aunque sí hubo resistencia por parte de los comandantes fieles al régimen monárquico, que forzó la capitulación de varias plazas (Guzmán Pérez, 2014).

El coronel Ángel Díaz del Castillo, comandante general de la plaza de Toluca y tenaz persecutor de insurgentes, preparó la defensa de la ciudad contra la trigarancia de enero a mayo de $1821,{ }^{54}$ pero en ese mismo mes, Iturbide mandó al coronel Vicente Filisola, jefe de la primera división perteneciente al Ejército Trigarante de Retaguardia -al mando del coronel Luis Quintanar-, para tomar Toluca, antes de ir a apoyar el sitio de Querétaro (Moreno Gutiérrez, 2014: 179). E1 17 de junio de 1821, una parte del regimiento del Escuadrón urbano de caballería de Toluca se unió a Filisola. Nicolás Gutiérrez, jefe del Escuadrón Urbano que defendía la ciudad, se quedó prácticamente sin fuerzas. El virrey Apodaca le mandó un refuerzo de infantería y al teniente coronel La Villa. Siguieron también a Filisola civiles de Toluca y pueblos circunvecinos, al mando de los capitanes Gonzalitos, Muñiz y Agustín Fuentes (Iracheta Cenecorta y Martínez García, 2002). Se incorporaron también el padre José Manuel Izquierdo, al mando de 350 hombres, así como Felipe Martínez, con 400 (Moreno Gutiérrez, 2014). Las tropas comandadas por Filisola llegaron a la hacienda "La Huerta", cerca de Zinacantepec. El comandante general de Toluca, el coronel Ángel Díaz del Castillo, al frente de 600 soldados peninsulares de infantería que llegaron a Toluca el 18 de junio, fue enviado a combatir a los insurgentes. Se le unieron las partidas realistas de caballería, con dos cañones con mucho parque, al mando del teniente Juan Madrazo (Iracheta Cenecorta y Martínez García, 2002). El 19 de junio, las tropas del gobierno llegaron a "La Huerta", donde la infantería insurgente, sin artillería, las esperaba. Castillo rompió un fuego de fusil y cañón sin dañar mucho a la infantería insurgente, cuya caballería se 
metió en el fuego realista causándole grandes destrozos y haciéndole perder los dos cañones. La derrota obligó a las tropas del gobierno a atrincherarse en la hacienda "La Huerta”, pues tenían impedida la retirada a Toluca (Iracheta Cenecorta y Martínez García, 2002). Esta victoria fue importante para el movimiento trigarante y una de las más sangrientas, pues ambos bandos reportaron cerca de 300 bajas (Moreno Gutiérrez, 2018). ${ }^{55}$ Castillo retuvo unos días el sitio a Toluca y posteriormente huyó a Lerma y después a México. Iturbide nombró al capitán Gonzalitos -antiguo insurgente- comandante trigarante en Toluca, pero lo sustituyó poco después por el coronel Agustín Fuentes. A principios de julio se produjo en Toluca una revuelta en contra del movimiento iturbidista, a cargo de tropas expedicionarias, acantonadas en la ciudad. Enviadas por Iturbide para sofocar una revolución en la ciudad de México, ${ }^{56}$ se insubordinaron en contra del comandante de Toluca, el coronel Agustín Fuentes, y de las autoridades civiles con quienes los toluqueños cerraron filas. A pedido de Fuentes, Iturbide envió 2000 hombres de todas armas, al mando de los generales José Joaquín de Herrera y José Antonio de Echávarri. Sin derramamiento de sangre, los insurrectos salieron de Toluca y a su retaguardia las fuerzas militares presididas por ambos generales. A mediados de julio, Toluca recibió a Iturbide "con las vivas y aclamaciones que se merecía" (Iracheta Cenecorta y Martínez García, 2002: 86-87).

La Jura de la Independencia en Toluca ya había sido celebrada con júbilo los días 12, 13 y 14 de mayo de 1821. El programa fue de carácter cívico-religioso, en él participó el subdelegado de Toluca, el licenciado Francisco Gutiérrez Rubín de Celis, hoy paladín de la Independencia y otrora enemigo de los insurgentes calificados por él como "inmorales y sediciosos". En su calidad de sota-síndico del Convento de San Francisco, recitó poemas de su autoría, cuyo contenido se unió a la ola de escritos difundidos en varias ciudades de Nueva España, al tiempo de la consumación de la Independencia, que revelan, como lo describe Moreno Romero
(2012), una atmósfera de entusiasmo y esperanza hacia la figura inmaculada y hasta divina de Agustín de Iturbide como libertador, como se consigna en este fragmento:

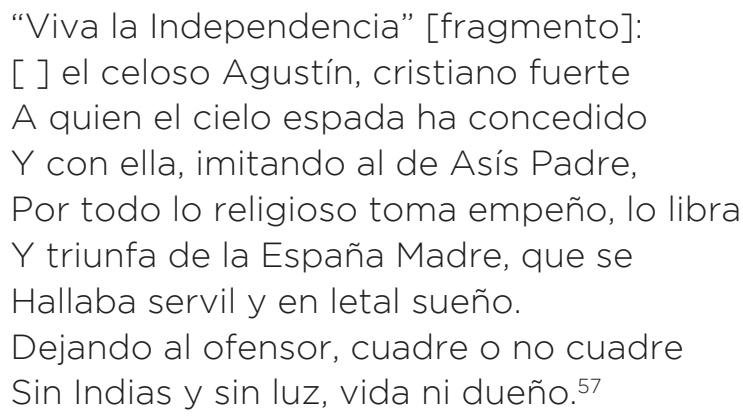

El 27 de septiembre de 1821 el Ejército Trigarante entró triunfante a la ciudad de México y al día siguiente se firmó el Acta de Independencia. Entre las fuerzas que arribaron figuraron las del Regimiento Provincial de Infantería de Toluca, con 250 elementos, y la Caballería del padre Juan Manuel Izquierdo, con 300 hombres. En octubre de 1821, Ramón Gutiérrez del Mazo, Jefe político e intendente de Toluca y de la Provincia de México, proclamó la Independencia en esa jurisdicción. Iniciaba la conformación de la nación mexicana.

\section{Conclusiones}

Toluca no había sido considerada como relevante en la historia de la guerra y consumación de la Independencia, hasta ahora. En este contexto, la pregunta de investigación planteada muestra -desde la perspectiva de la historia social y la escala local- las circunstancias históricas, políticas, sociales y económicas locales relacionadas con las experiencias y formas de incorporación y movilización de diversos estamentos sociales toluqueños en la guerra y consumación de la Independencia, en tres coyunturas significativas desde las cuales se produjo la acción colectiva: 1) La crisis política suscitada por el ayuntamiento capitalino -y su represión en 1808- y la agitación local, reflejo de esa crisis, que descubre la existencia de un grupo pluriétnico local descontento organizado; 2) La Conspiración de 1810 -con 
la participación de criollos, mestizos e indígenas, que permitió la identificación de actores sociales y sus motivaciones-, la cual fue reprimida severamente por los realistas y que provocó el viraje de los actores de la acción política a la político-militar. Reprimida la Conspiración de 1810, circunstancia que decidió el establecimiento de un férreo control político-jurídico territorial-militar realista, la participación social toluqueña quedó básicamente subsumida a la Junta Suprema Americana, que supervisó a las guerrillas dirigidas por líderes locales, así como a individuos que participaron en escaramuzas bélicas y en dos de las tres grandes batallas libradas en Zinacantepec y en Toluca, territorio muy disputado por insurgentes y realistas debido a su posición estratégica en el paso a la ciudad de México y a otras regiones. Asimismo, la sociedad sufrió el azote de enfermedades, violencia y exacciones económicas. En medio de la lucha militar destaca la implantación del primer ayuntamiento constitucional toluqueño que, si bien nació constreñido política y económicamente por los jefes militares realistas locales -algunos de los cuales lograron reacomodarse en el nuevo orden independiente-, se erigiría como el organismo representativo de los toluqueños; 3) La consumación de la Independencia tuvo como hito más importante la reimplantación del ayuntamiento y su progresiva expansión de un ámbito privativo de autoridad respecto a la administración de los asuntos públicos de la ciudad y sus alrededores, no sin la presión de autoridades superiores. En suma, el trabajo abona una perspectiva nueva -aunque inacabada- sobre el impacto del proceso independentista en una sociedad provincial. Queda pendiente su comparación con otras ciudades novohispanas.

\section{Notas}

2 Archivo General de la Nación (AGN), Correspondencia de Virreyes, Marqués de Croix y Marqués de Branciforte, vol. 189, exp. 1213, fs. 100-101: "Disculpando a la villa de Toluca del pago de la media anata por su antigüedad y pobreza", 1799.

3 Según este censo, el oficio de sastre fue muy relevante, ejercido por 99 individuos, todos criollos que concentraron 33\% de todo el sector artesanal (Bayardo Rodríguez, et al., 2018: 70-71).

4 AGN, Indiferente de Guerra, vol. 52 c: "Restablecimiento del Regimiento Provincial de Infantería de Toluca", 1794-1796; A GN, IG, Vol. 70: "Hojas de servicio de jefes y oficiales del Regimiento de Provincial de Infantería Toluca”, 1776-1796; AGN, Indiferente de Guerra, vol. 43b: "Hojas de servicio de oficiales del Regimiento Provincial de infantería de Toluca”, 1804; AGN, Indiferente de Guerra, vol. 24a: "Hojas de servicio de jefes y oficiales del Regimiento Provincial de Infantería de Milicias de Toluca y Regimiento Provincial de Dragones de Pátzcuaro, Michoacán", 1806.

5 Por ejemplo: AGN, Criminal, vol. 187, f. 171: “El virrey de la Nueva España envía a Juan Manuel Álvarez, la causa formada en el Regimiento Provincial de Infantería de Toluca contra José María Mercado y José María Montes de Oca, por robo dentro del cuartel; se les sentenció a dos meses de arresto, pero el auditor de guerra pidió se suspenda la sentencia hasta que su majestad decida", Primera serie, 1797; AGN, Criminal, vol. 719, exp. 7, fs. 138-181: "José María Mercado y José María Montes de Oca, soldados fueron acusados de robo por Augusto Almanza”, 1797-1800.

6 Don Nicolás Gutiérrez nació en España. Llegó a México como Capitán de Milicias, figuró como cabeza de la llamada Diputación de Toluca, creada en 1804, siendo su nombramiento de síndico procurador o del común (Romero Quiroz, 1973: 179). La Diputación fue un organismo que funcionó hasta 1810. Durante su bienio como corregidor (1808-1810), Gutiérrez también fue nombrado subdelegado en las causas de guerra y hacienda de la Intendencia de México por el virrey Iturrigaray, sustituto del titular Manuel Antonio de Falla Oruña, cargo que debía ostentar hasta 1810 (aunque en 1809 lo sustituyó Francisco Meana Gutiérrez). En 1810, el capitán Gutiérrez fue sustituido en el cargo de corregidor y subdelegado por Agustín de Arozqueta (AGN, Indiferente virreinal, Subdelegado, Caja 2875, exp. 1, f. 2, 1810). En 1812, reaparece como subdelegado y jefe del Escuadrón Urbano de Caballería de Toluca. En ese mismo año se establecieron los ayuntamientos prescritos por la Constitución de Cádiz; el de Toluca funcionó desde 1813. En 1814, el virrey Calleja nombró a Gutiérrez como jefe político del distrito de Toluca, al mismo tiempo detentó su puesto como comandante de las armas de Toluca, y por orden del virrey Calleja, miembro del Ayuntamiento. El 17 de diciembre de 1814 se disolvió el Ayuntamiento y la Diputación de Toluca de nuevo entró en funciones (AHMT, Actas de Cabildo, Libro de 1814-1823, 17 de diciembre de 1814). Esta diputación estuvo presidida por el subdelegado de Toluca y seis Diputados hasta 1820. En ese año funcionó de nueva cuenta el Ayuntamiento constitucional en el cual Gutiérrez fungía como comandante de las armas de Toluca y Alcalde constitucional de primer voto y presidente del Ayuntamiento toluqueño. Años des- 
pués regresó a España. Fue condecorado como Caballero de la Orden de Carlos III. Fungió como maestrante de la Caballería de Ronda. Murió en Santander en 1847.

7 El licenciado Francisco Gutiérrez Rubín de Celis, noble, abogado de la Real Audiencia de México (Romero Quiroz, 1973: 75), tenía una larga experiencia en el ejercicio del derecho criminal en el Valle de Toluca. Entre 1803 y 1808, Rubín de Celis sustituyó varias veces al corregidor subdelegado de Toluca, don Agustín de Arozqueta, al mismo tiempo que ejercía como asesor letrado y como síndico y primer diputado de la Diputación de 1806-1809. Hacia 1814, en su calidad de militar, Rubín de Celis fungió como comandante militar de Toluca en sustitución de Joaquín del Castillo Bustamante (AHMT, Sección Especial, c. 6, expediente [exp.] 396, 1840, foja [f.] 22). Entre 1815 y 1817 fue cabeza de la Diputación de Toluca que sustituyó al Ayuntamiento de 1814, así como juez subdelegado de Toluca y su jurisdicción (Gazeta del Gobierno de México, 1815: 759: 796). Permaneció al mismo tiempo como abogado de la Real Audiencia de México y se ostentó como alumno de su ilustre y real Colegio, asesor militar y alférez real. Como abogado, Rubín de Celis ejerció hasta 1823, en calidad de asesor letrado (AHPJEM, Toluca Penal, c. 1806-1808; c. 1809-1815, c. 1825).

8 AGN, Caminos y Calzadas, vol. 13, exp. 15, fs. 261-267: "Proposición que hace el corregidor de Toluca, Pedro de Larrea, sobre que sean utilizados los vagos y jornaleros sin empleo, que abundan en esta ciudad, en la construcción del nuevo camino [Toluca-México]", 1793.

9 AGN, Criminal, vol. 637, exp. 3, fs. 118-147: “Acusación por abuso de autoridad del alcalde mayor Francisco Sánchez contra los indios Tomás Aramburo, José Aramburo y Antonio Contreras", 1771; AGN, Tributos, vol. 28, exp. 3, fs. 105-111: "El gobernador de Toluca, Faustino Roberto, sobre que el corregidor impuso un embargo general de los bienes de todos los naturales deudores y no deudores de los tributos", 1761; AGN, Tributos, vol. 24, exp. 4, fs. 30-49: "Los naturales del pueblo de San Mateo Otzacatipan, jurisdicción de la ciudad de San José de Toluca, sobre que el corregidor les cobra tributos duplicados", 1771; AGN, Tributos, Vol. 53, exp. 27, fs. 405-418: "Los ministros generales sobre débito y fianza de tributos del corregidor y sustituto de Toluca”, 1796; AGN, Reales Cédulas Duplicadas, vol. 168, exp. 148, f. 2: "Informe de la queja presentada por Nicolás Vicente de Guadarrama, vecino de Toluca, contra los subdelegados, curas y hacendados de aquella provincia, entre otros, por hacer repartimientos contra lo que previene el artículo 12 de la instrucción de Intendentes de este reino", 1797; AGN, Reales Cédulas Originales, vol. 217, exp. 123, f.1.

10 Por ejemplo: AGN, Donativos y préstamos, vol. 21, exp. 26, fs. 198-219, "El corregidor de Toluca del Estado y marquesado del valle, Antonio de la Banda y Garcés, informa de lo colectado como donativos de su jurisdicción. Incluye un impreso con fecha de 1781, sobre la recaudación del donativo para la guerra", 1781-1783. 11 Tres ejemplos de otorgamiento de puestos o mando a peninsulares: Patente de capitán de la compañía de Milicias de Lerma del Regimiento Provincial de Infantería de Toluca, en Nueva España, a don Lorenzo Angulo y Guardamino (Secretaría del Despacho de Guerra de Indias), 1790; Regimiento de Infantería pro- vincial de Toluca: coronel, el marqués de Rivas Cacho, 1796; Regimiento de Infantería provincial de Toluca: tenencia a don José Francisco de Arechavala, 1797 (De Mayoralgo y Lodo Conde de los Acevedos, 2014). Algunos ejemplos de no otorgamiento de puestos, ascensos a criollos: AGN, Reales Cédulas Originales, vol. 165 b, exp. 172, f. 1/ Vol. 165 c, exp. 181, f. 1: “No se concede al conde De la Torre Cosío, capitán que fue del regimiento de infantería provincial de Toluca, la merced de hábito que solicita", 1796; AGN, Reales Cédulas Originales, vol. 171, exp. 230, f. 1: "Negando el grado de teniente coronel del ejército con agregación al provincial de México a Francisco Alonso Terán, capitán del regimiento de infantería de Toluca", 1798; AGN, Reales Cédulas Originales, vol. 184, exp. 50, f. 1: "Negando la tenencia veterana del Cuerpo de Cazadores de las Tres Villas a Pedro Antonio Muñoz, subteniente del Regimiento Provincial de Infantería de Toluca de Toluca", 1802; AGN, Reales Cédulas Originales, vol. 195, exp. 49, f. 1: "Negando el rey a Diego González Peredo, teniente de granaderos del regimiento de infantería provincial de Toluca, el grado de capitán que solicitó”, 1805; AGN, Reales Cédulas Originales, vol. 196, exp. 218, f. 1: "Negando a Miguel Paz y Pimentel, ayudante veterano del regimiento de infantería provincial de Toluca, el grado que solicita", 1805; AGN, Reales Cédulas Originales, vol. 200, exp. 40, f. 1: "Negando a Francisco Alonso de Terán su reposición en el empleo de capitán que se le quitó, y al mismo tiempo conferirle la primera compañía que vacase en el regimiento de infantería provincial de Toluca, 1808; AGN, Reales Cédulas Originales, vol. 217, exp. 123, f. 1.: Deniega el rey, todas las solicitudes hechas por Ángel Pascual Casabal, capitán retirado del regimiento de infantería de Toluca, quien pretende el grado de teniente coronel, una pensión, un gobierno militar o un empleo en la real hacienda, 1817". 12 Ante una nueva petición de donativo, en septiembre de 1810 Sáenz se comunicó con el virrey para pedirle que informara al Supremo Consejo de Regencia que podría solo con 500 pesos, pues ya eran cinco donativos dados en menos de dos años, que ascendieron a 2575 pesos, más 100 para los patriotas de Zaragoza: AGN, Donativos y Préstamos, vol. 4, fs. 245-247: "Negativa de Ignacio García Sáenz al pago del Donativo Gracioso", 1810. También, la cesión de su sueldo, 1000 pesos en 1808, de Capitán del Regimiento Provincial de Infantería de Toluca: AGN, Donativos y Préstamos, vol. 201, exp. 102, fs. 221: "Notificación al virrey José de Iturrigaray por Miguel Castaños, del donativo que ofreció Ignacio García Sáenz, capitán del Regimiento Provincial de Infantería de Toluca y ayudante general de las tropas acantonadas, de 1000 pesos", 1808. En 1809 prestó 5000 pesos. Como encargado del vestuario del Regimiento, a cuenta de la Real Hacienda había suplido 20,000, saliendo descubierto con 8000 pesos. Solicitaba que se le tomaran en cuenta "estos cortos servicios".

13 La evidencia de los mestizos como tributarios, en: AGN, Tributos, vol. 54, exp. 11, fs. 170-181: "Pedro de Larrea y Salcedo, corregidor de la jurisdicción de Toluca, solicitando se le declare libre de responsabilidad por el tributo de mulatos y vagos, quienes, en términos de pago de tributo, eran los hijos de mujeres negras o mulatas, obligadas a pagarlo" (Castañeda, 2014: 156).

14 AGN, Tributos, vol. 40, exp. 8, fs. 76-80: "Instancia de los soldados del Regimiento Provincial de Infantería 
de Toluca, solicitando no paguen tributo sus padres", 1779.

15 AGN, Criminal, vol. 596, exp. 16, fs. 333-340: "El sargento desertor del Regimiento de Infantería José López pide que se le devuelva su cargo", 1801; AGN, Criminal, vol. 647, exp. 10, fs. 193-221: "Acusación en contra de Ildefonso Guarros, Vicente Correro, Martín Francisco Bernal y José María Mata por deserción", 1805; AGN, Criminal, vol. 494, exp. 6, fs. 166-200: "El teniente Manuel Villavicencio acusado de deserción", 1810; AGN, Criminal, vol. 428, exp. 1, fs. 1-133: "Acusación de deserción contra el sargento segundo Froylán Fernández y Santiago Paredes, Manuel Cervantes, Diego Flores y Bárbara Arias", 1815.

16 Por Ejemplo: AGN, Criminal, vol. 690, exp. 1, fs. 1-51: "Juan Ávalos, soldado. Por realizar juntas secretas y abuso de autoridad", 1804; AGN, Infidencias, vol. 5, exp. 7, 21 fs.: "Luis Flores, sargento primero de infantería del Regimiento Provincial de Infantería de Toluca, fue denunciado por dos de sus compañeros con quien se emborrachó, acusándolo 'por haber vertido palabras favorables a los insurgentes'. Fue enviado a La Habana", 1810-1813; AGN, Infidencias, vol. 160, exp. 16, f. 2: "El coronel Telésforo de los Ríos, acusado de haber sido coronel entre los insurgentes", 1813; AGN, Infidencias, vol. 53, exp. 9, 81 fs.: "Se fugó, regresando con los rebeldes para después ser indultado por presentarse voluntariamente", 1813; AGN, Infidencias, vol. 94, exp. 1,40 fs.: "José María Avilés, soldado del Regimiento de Toluca, acusado de deserción y sospecha de infidencia. Condenado a tres años de recargo en el servicio: el virrey agravó la sentencia, al imponerle tres años de obras públicas", 1815-1816.

17 AGN, Infidencias, Vol. 172, exp. 66, f. 492: "Consulta sobre la prisión de fray Francisco Antelo”, 1812.

18 Sin embargo, fray José Policarpo Berra, juez eclesiástico de Toluca en 1815, juró lealtad a España, junto con los miembros de la Diputación de Toluca, y apoyó la censura de la prensa insurgente.

19 AGN, Infidencias, vol. 175, exp. 103, f. 440: "El comandante Joaquín Castillo Bustamante avisa de una carta que fue hallada en Tenango entre los papeles de los insurgentes y que ella probaba bien la conducta del cura de Toluca, fray Francisco Gómez", 1812; AGN, Infidencias, vol. 175, exp. 104, f. 440: "Ocurso del religioso fray Francisco Gómez reclamando su separación del curato de Toluca y habiendo mandado su excelencia que se reuniesen los antecedentes de esta instancia se entregaron al gobierno el 20 de mayo", 1817.

20 AGN, Criminal, vol. 219, exp. 16, fs. 302-332: Expediente que se formó para averiguar el origen, autor y fin de cierto alistamiento o convocatoria de hombres diestros en el manejo de las armas, 1808.

21 AGN, Infidencias, vol. 165, exp. 42, f. 4: "Los vecinos de Toluca solicitan al virrey no cambie al corregidor interino de esa jurisdicción, Nicolás Gutiérrez", 1808. 22 Según Víctor Mínguez, la Jura consistía en que "todas las ciudades del reino proclamaban ante un monarca físicamente ausente, pero materializado simbólicamente a través del arte, su lealtad al nuevo rey que accedía al trono. Se trata de un ceremonial castellano que sólo será impuesto a los territorios de la antigua Corona de Aragón en el siglo XVIII, cuando los borbones sustituyan a los Austrias y la monarquía pactista de los segundos sea reemplazada por la monarquía absoluta de los primeros. En Nueva España la procla- mación real fue practicada durante todo el virreinato en las plazas mayores de las urbes" (2007: 247).

23 AGN, Historia, Tomo 405, Exp. 14, fs. 13-15, Secretaría del Virreinato: "Jura en Toluca del Rey Fernando VII", 1809.

24 La pugna entre Gutiérrez Rubín de Celis y don Nicolás Gutiérrez adquirió visos casi grotescos, cuando el primero la trasladó al campo del honor. Así, Rubín de Celis apeló al virrey para que se hiciera la Jura con la vistosidad programada, por el sonrojo que le causaría no hacer la Jura, estando en juego su obediencia como vasallo del rey y su prestigio como Hidalgo y descendiente de la casa solariega de Celis y hasta su vida por las burlas y amenazas en pasquines, carteles y anónimos, que lo obligarían a irse con su familia a vivir a otro lugar: AGN, Historia, Tomo 405, Exp. 14, fs. 13-14, Secretaría del Virreinato: "Jura en Toluca del Rey Fernando VII", 1809.

25 A GN, Donativos y préstamos, vol. 11, exp. 48, fs. 356 358: "Nicolás Gutiérrez envía la lista de lo recaudado en Toluca y sus pueblos por concepto de donativo y préstamo", 1809.

26 A GN, Donativos y préstamos, vol. 11, exp. 48, fs. 356358: "Nicolás Gutiérrez envía la lista de lo recaudado en Toluca y sus pueblos por concepto de donativo y préstamo", 1809.

27 "Informe del coronel Lorenzo Angulo Guardamino sobre la Jura del Rey Fernando VII en Toluca" (Gazeta del Gobierno de México, 1814: 726-729). Sin embargo, en un documento posterior, el licenciado Francisco Gutiérrez Rubín de Celis rememoró la celebración de la Jura fernandina, "con el esplendor que merecería" presumiendo que él pagó los gastos. También dejó asentado que luego de la Jura fue apresado en Toluca por los insurgentes (y luego rescatado), decidiéndose a morir "antes que hacerse partidario de los traidores" (Gazeta del Gobierno de México, 1815: 796-798).

28 AGN, Infidencias, vol. 4, exp. 6, 7 fs.: "Denuncia anónima referente a especies sediciosas vertidas en Toluca", 1809.

29 Conferencia de la doctora Guadalupe Jiménez Codinach en El Colegio del Estado de Hidalgo (17 de octubre de 2014). En ella afirmó la existencia de dicha Junta Secreta con base en el proceso llevado contra Ignacio Allende, antes de su fusilamiento. Dicho proceso se radicó en Chihuahua y depositado luego en el Archivo General de la Nación.

30 Margarita García Luna, "Una conspiración insurgente en Toluca, 1810".

31 AGN, Criminal, vol. 191, exp. 10, fs. 338-368: "Expediente que contiene la causa que formó José Suárez, teniente provincial, sobre la culpa que motivó fueran remitidos a la cárcel de Toluca los reos: Marcelo Díaz, Felipe Pereyra, Mariano Sánchez, Mariano Rivas, Domingo Reyes, José Zarco y Juan Reyes", 1810.

32 AGN, Indiferente virreinal, Subdelegado, Caja 2875, exp. 1, f. 2, 1810 (Pérez Hernández, 2017: 233).

33 Algunos de estos personajes purgaron la pena; otros, escaparon de la prisión y se lanzaron a la lucha armada como Gerardo Duén, Ángel Arias y José María Olascoaga. Este último sería indultado en 1815. Al parecer, otros insurgentes que habían tomado las armas - José Mariano Espinosa y Mariano Farfán- habían muerto y Bernardino Vega ya retirado y pobre vivía en la ciudad de México.

34 AGN, Criminal, vol. 191, exp. 10, fs. 338-368: "Expe- 
diente que contiene la causa que formó José Suárez, teniente provincial, sobre la culpa que motivó fueran remitidos a la cárcel de Toluca los reos: Marcelo Díaz, Felipe Pereyra, Mariano Sánchez, Mariano Rivas, Domingo Reyes, José Zarco y Juan Reyes, 1810”.

35 AGN, Criminal, vol. 707, exp. 7, fs. 111-362: "Nicolás Llera, Jorge León, Sixto Ricardo Ramírez, José Lucas Guadarrama y varios acusados del delito de insurgencia”, 1810; AGN, Criminal, vol. 216, exp. 2, fs. 80-148: "Causa criminal de oficio contra los que aprehendieron el 15 de octubre por sospecha de sedición", 1810; AGN, Criminal, vol. 217, exp. 15, fs. 228-234: "Incidente que se suscitó en la causa que se les tomó a varios individuos presos por infidencias", 1810; AGN, Criminal, vol. 707, exp. 6, fs. 106-110: "Mariano Garduño, acusado por abuso de autoridad en contra de José de la Cruz y Jacinto Romero", 1810; AGN, Criminal, vol. 707, exp. 7, fs. 111-362: "Nicolás Llera, Jorge León, Sixto, Ricardo Ramírez, José Lucas Guadarrama y varios, acusados de insurgentes", 1810; AGN, Criminal, vol. 191, exp. 11, fs. 369-398: "Causa criminal que se les siguió a los reos: Felipe Pereyra, Marcelo Díaz, Domingo Reyes y José Zarco", 1811. Observaciones: esta causa se derivó del expediente abierto en 1810 y que aparece en los expedientes 10, 12, 13 y 14, los cuales versan sobre el mismo delito.

36 AGN, Criminal, vol. 169, exp. 20, fs. 161-226: "Información sobre pasquines en la ciudad de Toluca emitidos por los insurgentes", 1810.

37 Tres ejemplos de la actuación de la Junta: AGN, Infidencias, vol. 177, exp. 150, f., 379: "José Agustín Becerril, Ponciano López e Hipólito García acusados de infidencia fueron sentenciados a ser fusilados. Otras 13 personas fueron aprehendidas por ser integrantes de la gavilla 'del sanguinario Trejo' y condenados a pertenecer por 10 años al Fijo de La Habana, Cuba", 1813; A GN, Infidencias, vol. 48, exp. 10, 13 fs.: "Toribio Reza y Francisco Carrasca, fueron aprehendidos con las armas en la mano después de haber permanecido con los insurgentes, se creyó en su palabra que iban a presentarse voluntariamente en solicitud de indulto, pero fueron condenados a cuatro años de servicio en la marina”, 1816; AGN, Criminal, vol. 217, exp. 17, fs. 249-270: "Francisco Salamanca, Gertrudis Espinoza, Mariano Espinoza Marcelino Vega, Joaquín de la Llera, Mariano Garduño, Mariano Farfán, Antonio Ordoñez, Juan Domingo y el presbítero Joaquín Omaña, estando presos desde 1810 solicitaron su libertad, pues fueron acusados de sedición en la época de la insurgencia, porque formaron parte de la Conspiración criolla de Toluca en ese año", 1819.

38 AGN (sin ramo), "Proceso en contra de Alejo de la Cruz, Rufino Sevario y otros acusados de insurgentes", Toluca, 1811. Documento de archivo personal (Pérez Silva, 2021a).

39 Archivo Parroquial de El Sagrario, Toluca, Entierros de indios mexicanos, Libro 7, 1809-1813, Caja 5/ Defunciones/ 1805-1815/ 4 vol./ Caja 77.

40 AGN (sin ramo), "Informe del cura ministro de Toluca, fray Francisco Gómez al Provisor y Capitular sobre un inminente ataque al pueblo de Tlacotepec", 9 de junio de 1811, Documento del archivo personal (Pérez Silva, 2021b).

41 El 14 de abril de 1815 Toluca sufrió otra incursión armada; el teniente coronel Nicolás Gutiérrez informó que Vicente Vargas estuvo en la ciudad con sus hombres que se presentaron "por todas las cortaduras causando terror" (Beltrán Silva, 2018: 114-115). En 1818 Vargas aprehendió a Leona Vicario y a su esposo Andrés Quintana Roo cerca de Sultepec. En ese mismo año fue indultado con toda su partida; incluso, quedó al mando de una compañía de realistas en Tenancingo, pero en septiembre de 1819 regresó a la insurgencia. En ese mismo año, el teniente coronel de la Villa de Guadalupe, don Juan Madrazo, y el capitán de Urbanos de Toluca, don José Vicente González, sorprendieron a Vargas cerca de Zumpahuacán, siendo fusilado en Toluca el 14 de octubre de 1819 (Beltrán Silva, 2018: 174). 42 Se refiere a la toma de Cuautla por los insurgentes, iniciada el 12 de febrero de 1812, durante la campaña del generalísimo José María Morelos, lo cual era importante por su cercanía con la ciudad de México, aunque los insurgentes querían tomar Puebla. Como la ciudad de México estaba rodeada por partidas insurgentes, los realistas atacaron Cuautla e Izúcar para evitar la reunión de fuerzas rebeldes en algunos de estos dos puntos. Los realistas sitiaron la ciudad, cortaron el agua, lo cual, junto con el hacinamiento, la falta de higiene y poca alimentación, creó un ambiente idóneo para la aparición del tifo (Sánchez Uriarte, 1997: 40).

43 AHMT, Actas de Cabildo, 9 de marzo de 1814.

44 "Lorenzo Angulo Guardamino" (El Valle de Carranza, 2017; Auñamendi Eusko Entziklopedia, s.f.; Martínez Borrallo, 2017: 157; A GN, Reales cédulas originales, vol. 147, exp. 157, f. 1: "Se confiere patente de Capitán de la compañía de Milicias de Lerma de Regimiento Provincial de Infantería de Toluca a Lorenzo de Angulo y Guardamino", 1790; José Miguel de Mayolargo y Lodo Conde de los Acevedos, 2014; Herrejón Peredo, 2007. 45 El ayuntamiento adoptó la importante medida de terminar con el desorden del ramo de arbitrios y el de las contribuciones de las tiendas de ropa y las de pulpería, las tocinerías, vinaterías y pulquerías, así como las mesas de trucos y billares y lo que pagaban los puestos de la plaza y las cantinas (AHMT, Actas de cabildo, 5 de marzo de 1814).

46 El resto de los integrantes: Mariano Garduño, Lázaro José de Castro, Francisco de La Ribera, Manuel de Lechuga, José Antonio Fernández Castañón, Juan Francisco de Herrera, Justo Valdés, Pedro de Linares, Lic. Juan Manuel Azorrey.

47 AHMT, Actas de Cabildo, libro de 1814-1823, 9 de julio de 1814.

48 AHMT, Actas de Cabildo, libro de 1814-1823, 17 de diciembre de 1814.

49 "Composición alegórica en celebridad del Juramento de la Constitución política de la Monarquía Española solemnizado en la ciudad de Toluca á 11 de junio de 1820, por el Lic. Andrés Quintana Roo" (Quintana Roo, 1820).

50 AHMT, Actas de Cabildo, 27 de marzo de 1821.

51 AHMT, Actas de Cabildo, 9 y 16 de enero, 27 de marzo de 1821.

52 AHMT, Actas de Cabildo, 29 de agosto de 1820; 9 , 16, 23 y 30 de enero, 6 y 27 de febrero de 1821.

53 Por ejemplo, AGN, Criminal, vol. 531, exp. 16, fs. $224-$ 240: "En 1821 el ahora sargento coronel Nicolás Gutiérrez tuvo problemas por el rango con Francisco de Aranda, teniente coronel", 1821; AGN, Criminal, vol. 522, exp. 12, fs. 408-414: "José María Lozada, soldado de la compañía de caballería de realistas fieles de Toluca, acusado de deserción”, 1818; "AGN, Criminal, vol. 143 
exp. 3, 18 fs.: "Sumaria instruida en Toluca a los tenientes Manuel Murillo y Bernardo Toral, sospechosos de haberse pasado a las fuerzas rebeldes de Iturbide: fueron absueltos y continuaron en el servicio, pero Toral sufrió dos meses de arresto", 1819.

54 AHMT, Actas de Cabildo, alistando a los ciudadanos para defender la ciudad, 27 de marzo; necesidad de dinero para las obras de fortificación del Carmen, Beaterio, Cóporo y El Calvario, que se están construyendo por disposición del comandante general de la plaza (Toluca), coronel Don Ángel Díaz del Castillo, 28 de mayo. En cabildo se informa sobre los gastos necesarios para hacer las fortificaciones de parapetos, cortaduras y reductos en la ciudad, 5 de junio de 1821. 55 En la Crónica de 1840 se afirma que las tropas del gobierno tuvieron más de 400 muertos, entre ellos algunos oficiales, y más de 100 heridos; los independentistas, 20 muertos, entre ellos tres oficiales y muy pocos heridos (Iracheta Cenecorta y Martínez García, 2002: 85).

56 Se trata del golpe de Estado del subinspector de Artillería Francisco Novella, en la ciudad de México, el 5 de julio de 1821, que comandó a un grupo de oficiales peninsulares y novohispanos empeñados en apoyar al régimen virreinal ante el deterioro de la situación militar entre mayo y junio de 1821. Destituyeron al virrey Juan José Ruiz de Apodaca, lo cual significó la destrucción definitiva de la legitimidad del régimen español. Iturbide se opuso al golpe y rechazó el "gobierno intruso” de Novella (Moreno Gutiérrez, 2014).

57 "Poesías que se presentaron en la vistosa Portería del Convento parroquial de Nuestro padre San Francisco de Toluca en los tres días de la Jura de nuestra deseada Independencia, que fueron 12, 13 y 14 de mayo de 1821. Su autor, el hermano sota-síndico del referido Convento, licenciado don Francisco Gutiérrez Rubín de Celis" (Gutiérrez Rubín de Celis, 1821).

\section{Fuentes consultadas}

\section{Archivos}

AGN (Archivo General de la Nación) (1761), "El gobernador de Toluca, Faustino Roberto, sobre que el corregidor impuso un embargo general de los bienes de todos los naturales deudores y no deudores de los tributos", Tributos, vol. 28, exp. 3, fs. 105-111.

AGN (Archivo General de la Nación) (1771), "Acusación por abuso de autoridad del alcalde mayor Francisco Sánchez contra los indios Tomás Aramburo, José Aramburo y Antonio Contreras", Criminal, vol. 637, exp. 3, fs. 118-147.

AGN (Archivo General de la Nación) (1771), "Los naturales del pueblo de San Mateo Otzacatipan, jurisdicción de la ciudad de San José de Toluca, sobre que el corregidor les cobra tributos duplicados", Tributos, vol. 24, exp. 4, fs. 30-49.

AGN (Archivo General de la Nación) (17761796), "Hojas de servicio de jefes y oficiales del Regimiento de Provincial de Infantería Toluca", Indiferente General, vol. 70.

AGN (Archivo General de la Nación) (1779), "Instancia de los soldados del Regimiento Provincial de Infantería de Toluca, solicitando no paguen tributo sus padres", Tributos, vol. 40, exp. 8, fs. 7680.

AGN (Archivo General de la Nación) (17811783), "El corregidor de Toluca del Estado y marquesado del valle, Antonio de la Banda y Garcés, informa de lo colectado como donativos de su jurisdicción. Incluye un impreso con fecha de 1781, sobre la recaudación del donativo para la guerra", Donativos y préstamos, vol. 21, exp. 26, fs. 198-219.

AGN (Archivo General de la Nación) (1790), "Se confiere patente de Capitán de la compañía de Milicias de Lerma de Regimiento Provincial de Infantería de Toluca a Lorenzo de Angulo y Guardamino", Reales cédulas originales, vol. 147, exp. 157, f. 1.

AGN (Archivo General de la Nación) (1793), "Proposición que hace el corregidor de Toluca, Pedro de Larrea, sobre que sean utilizados los vagos y jornaleros sin empleo, que abundan en esta ciudad, en la construcción del nuevo camino [Toluca-México]", Caminos y Calzadas, vol. 13, exp. 15, fs. 261-267.

AGN (Archivo General de la Nación) (17941796), "Restablecimiento del Regimiento Provincial de Infantería de Toluca", Indiferente de Guerra, vol. 52 c.

AGN (Archivo General de la Nación) (1796), "Los ministros generales sobre débito y fianza de tributos del corregidor y sustituto de Toluca", Tributos, vol. 53, exp. 27, fs. 405-418. 
AGN (Archivo General de la Nación) (1796), "No se concede al conde De la Torre Cosío, capitán que fue del regimiento de infantería provincial de Toluca, la merced de hábito que solicita", Reales Cédulas Originales, vol. 165 b, exp. 172, f. 1/ Vol. 165 c, exp. 181, f. 1.

AGN (Archivo General de la Nación) (1797), "Informe de la queja presentada por Nicolás Vicente de Guadarrama, vecino de Toluca, contra los subdelegados, curas y hacendados de aquella provincia, entre otros, por hacer repartimientos contra lo que previene el artículo 12 de la instrucción de Intendentes de este reino", Reales Cédulas Duplicadas, vol. 168, exp. 148, f. 2.

AGN (Archivo General de la Nación) (1797), "El virrey de la Nueva España envía a Juan Manuel Álvarez, la causa formada en el Regimiento Provincial de Infantería de Toluca contra José María Mercado y José María Montes de Oca, por robo dentro del cuartel; se les sentenció a dos meses de arresto, pero el auditor de guerra pidió se suspenda la sentencia hasta que su majestad decida", Primera serie, Criminal, vol. 187, f. 171.

AGN (Archivo General de la Nación) (1797), "Pedro de Larrea y Salcedo, corregidor de la jurisdicción de Toluca, solicitando se le declare libre de responsabilidad por el tributo de mulatos y vagos, quienes, en términos de pago de tributo, eran los hijos de mujeres negras o mulatas, obligadas a pagarlo", Tributos, vol. 54, exp. 11, fs. 170-181.

AGN (Archivo General de la Nación) (17971800), "José María Mercado y José María Montes de Oca, soldados fueron acusados de robo por Augusto Almanza", Criminal, vol. 719, exp. 7, fs. 138-181.

AGN (Archivo General de la Nación) (1798), "Negando el grado de teniente coronel del ejército con agregación al provincial de México a Francisco Alonso Terán, capitán del regimiento de infantería de Toluca", Reales Cédulas Originales, vol. 171, exp. 230, f. 1.
AGN (Archivo General de la Nación) (1799), "Disculpando a la villa de Toluca del pago de la media anata por su antigüedad y pobreza", Correspondencia de Virreyes, Marqués de Croix y Marqués de Branciforte, vol. 189, exp. 1213, fs. 100-101.

AGN (Archivo General de la Nación) (1801), "El sargento desertor del Regimiento de Infantería José López pide que se le devuelva su cargo", Criminal, vol. 596, exp. 16, fs. 333-340.

AGN (Archivo General de la Nación) (1802), "Negando la tenencia veterana del Cuerpo de Cazadores de las Tres Villas a Pedro Antonio Muñoz, subteniente del Regimiento Provincial de Infantería de Toluca de Toluca", Reales Cédulas Originales, vol. 184, exp. 50, f. 1.

AGN (Archivo General de la Nación) (1804), "Hojas de servicio de oficiales del Regimiento Provincial de infantería de Toluca", Indiferente General, vol. 43b.

AGN (Archivo General de la Nación) (1804), "Juan Ávalos, soldado. Por realizar juntas secretas y abuso de autoridad", Criminal, vol. 690, exp. 1, fs. 1-51.

AGN (Archivo General de la Nación) (1805), "Acusación en contra de Ildefonso Guarros, Vicente Correro, Martín Francisco Bernal y José María Mata por deserción", Criminal, vol. 647, exp. 10, fs. 193-221.

AGN (Archivo General de la Nación) (1805), "Negando el rey a Diego González Peredo, teniente de granaderos del regimiento de infantería provincial de Toluca, el grado de capitán que solicitó", Reales Cédulas Originales, vol. 195, exp. 49, f. 1.

AGN (Archivo General de la Nación) (1805), "Negando a Miguel Paz y Pimentel, ayudante veterano del regimiento de infantería provincial de Toluca, el grado que solicita", Reales Cédulas Originales, vol. 196, exp. 218, f. 1. 
AGN (Archivo General de la Nación) (1806), "Hojas de servicio de jefes y oficiales del Regimiento Provincial de Infantería de Milicias de Toluca y Regimiento Provincial de Dragones de Pátzcuaro, Michoacán", Indiferente General, vol. 24a.

AGN (Archivo General de la Nación) (1808), "Negando a Francisco Alonso de Terán su reposición en el empleo de capitán que se le quitó, y al mismo tiempo conferirle la primera compañía que vacase en el regimiento de infantería provincial de Toluca", Reales Cédulas Originales, vol. 200, exp. 40, f. 1.

AGN (Archivo General de la Nación) (1808), "Notificación al virrey José de Iturrigaray por Miguel Castaños, del donativo que ofreció Ignacio García Sáenz, capitán del Regimiento Provincial de Infantería de Toluca y ayudante general de las tropas acantonadas, de 1000 pesos", Donativos y Préstamos, vol. 201, exp. 102, fs. 221.

AGN (Archivo General de la Nación) (1808), "Expediente que se formó para averiguar el origen, autor y fin de cierto alistamiento o convocatoria de hombres diestros en el manejo de las armas", Infidencias, vol. 219, exp. 16, fs. 302-332.

AGN (Archivo General de la Nación) (1808), "Los vecinos de Toluca solicitan al virrey no cambie al corregidor interino de esa jurisdicción, Nicolás Gutiérrez", Infidencias, vol. 165, exp. 42, f. 4.

AGN (Archivo General de la Nación) (1809), "Jura en Toluca del Rey Fernando VII", Historia, Tomo 405, Exp. 14, fs. 13-15, Secretaría del Virreinato.

AGN (Archivo General de la Nación) (1809), "Nicolás Gutiérrez envía la lista de lo recaudado en Toluca y sus pueblos por concepto de donativo y préstamo", Donativos y préstamos, vol. 11, exp. 48, fs. 356-358.

AGN (Archivo General de la Nación) (1809), "Denuncia anónima referente a especies sediciosas vertidas en Toluca", Infidencias, vol. 4, exp. 6, 7 fs.
AGN (Archivo General de la Nación) (1810), "Expediente que contiene la causa que formó José Suárez, teniente provincial, sobre la culpa que motivó fueran remitidos a la cárcel de Toluca los reos: Marcelo Díaz, Felipe Pereyra, Mariano Sánchez, Mariano Rivas, Domingo Reyes, José Zarco y Juan Reyes", Criminal, vol. 191, exp. 10, fs. 338-368.

AGN (Archivo General de la Nación) (1810), "Negativa de Ignacio García Sáenz al pago del Donativo Gracioso", Donativos y Préstamos, vol. 4, fs. 245-247.

AGN (Archivo General de la Nación) (1810), "Nombramiento de Agustín de Arozqueta como corregidor y subdelegado, en sustitución del coronel Nicolás Gutiérrez", Indiferente virreinal, Subdelegado, Caja 2875, exp. 1, f. 2.

AGN (Archivo General de la Nación) (1810), "Expediente que contiene la causa que formó José Suárez, teniente provincial, sobre la culpa que motivó fueran remitidos a la cárcel de Toluca los reos: Marcelo Díaz, Felipe Pereyra, Mariano Sánchez, Mariano Rivas, Domingo Reyes, José Zarco y Juan Reyes", Criminal, vol. 191, exp. 10, fs. 338-368.

AGN (Archivo General de la Nación) (1810), "El teniente Manuel Villavicencio acusado de deserción", Criminal, vol. 494, exp. 6, fs. 166-200.

AGN (Archivo General de la Nación) (1810), "Nicolás Llera, Jorge León, Sixto Ricardo Ramírez, José Lucas Guadarrama y varios acusados del delito de insurgencia”, Criminal, vol. 707, exp. 7, fs. 111-362.

AGN (Archivo General de la Nación) (1810), "Causa criminal de oficio contra los que aprehendieron el 15 de octubre por sospecha de sedición", Criminal, vol. 216, exp. 2, fs. 80-148.

AGN (Archivo General de la Nación) (1810), "Incidente que se suscitó en la causa que se les tomó a varios individuos presos por infidencias", Criminal, vol. 217, exp. 15, fs. 228-234. 
AGN (Archivo General de la Nación) (1810), "Mariano Garduño, acusado por abuso de autoridad en contra de José de la Cruz y Jacinto Romero", Criminal, vol. 707, exp. 6, fs. 106-110.

AGN (Archivo General de la Nación) (1810), "Nicolás Llera, Jorge León, Sixto, Ricardo Ramírez, José Lucas Guadarrama y varios, acusados de insurgentes", Criminal, vol. 707, exp. 7, fs. 111-362.

AGN (Archivo General de la Nación) (1810), "Información sobre pasquines en la ciudad de Toluca emitidos por los insurgentes", Criminal, vol. 169, exp. 20, fs. 161-226.

AGN (Archivo General de la Nación) (18101813), "Luis Flores, sargento primero de infantería del Regimiento Provincial de Infantería de Toluca, fue denunciado por dos de sus compañeros con quien se emborrachó, acusándolo 'por haber vertido palabras favorables a los insurgentes'. Fue enviado a La Habana", Infidencias, vol. 5, exp. 7, 21 fs.

AGN (Archivo General de la Nación) (1811), "Causa criminal que se les siguió a los reos: Felipe Pereyra, Marcelo Díaz, Domingo Reyes y José Zarco", Criminal, vol. 191, exp. 11, fs. 369-398.

AGN (Archivo General de la Nación) (1812), "Consulta sobre la prisión de fray Francisco Antelo", Infidencias, vol. 172, exp. 66, f. 492.

AGN (Archivo General de la Nación) (1812), "El comandante Joaquín Castillo Bustamante avisa de una carta que fue hallada en Tenango entre los papeles de los insurgentes y que ella probaba bien la conducta del cura de Toluca, fray Francisco Gómez", Infidencias, vol. 175, exp. 103, f. 440.

AGN (Archivo General de la Nación) (1813), "José Agustín Becerril, Ponciano López e Hipólito García acusados de infidencia fueron sentenciados a ser fusilados. Otras 13 personas fueron aprehendidas por ser integrantes de la gavilla 'del sanguinario Trejo' y condenados a per- tenecer por 10 años al Fijo de La Habana, Cuba", Infidencias, vol. 177, exp. 150, f., 379 .

AGN (Archivo General de la Nación) (1813), "El coronel Telésforo de los Ríos, acusado de haber sido coronel entre los insurgentes", Infidencias, vol. 160, exp. 16, f. 2.

AGN (Archivo General de la Nación) (1813), "Se fugó, regresando con los rebeldes para después ser indultado por presentarse voluntariamente", Infidencias, vol. 53, exp. 9, $81 \mathrm{fs}$.

AGN (Archivo General de la Nación) (1815), "Acusación de deserción contra el sargento segundo Froylán Fernández y Santiago Paredes, Manuel Cervantes, Diego Flores y Bárbara Arias", Criminal, vol. 428, exp. 1, fs. 1-133.

AGN (Archivo General de la Nación) (18151816), "José María Avilés, soldado del Regimiento de Toluca, acusado de deserción y sospecha de infidencia. Condenado a tres años de recargo en el servicio: el virrey agravó la sentencia, al imponerle tres años de obras públicas", Infidencias, vol. 94, exp. 1,40 fs.

AGN (Archivo General de la Nación) (1816), "Toribio Reza y Francisco Carrasca, fueron aprehendidos con las armas en la mano después de haber permanecido con los insurgentes, se creyó en su palabra que iban a presentarse voluntariamente en solicitud de indulto, pero fueron condenados a cuatro años de servicio en la marina", Infidencias, vol. 48, exp. 10, 13 fs.

AGN (Archivo General de la Nación) (1817), "Ocurso del religioso fray Francisco Gómez reclamando su separación del curato de Toluca y habiendo mandado su excelencia que se reuniesen los antecedentes de esta instancia se entregaron al gobierno el 20 de mayo", Infidencias, vol. 175, exp. 104, f. 440.

AGN (Archivo General de la Nación) (1817), "Deniega el rey, todas las solicitudes hechas por Ángel Pascual Casabal, ca- 
pitán retirado del regimiento de infantería de Toluca, quien pretende el grado de teniente coronel, una pensión, un gobierno militar o un empleo en la real hacienda", Reales Cédulas Originales, vol. 217, exp. 123, f. 1.

AGN (Archivo General de la Nación) (1818), "José María Lozada, soldado de la compañía de caballería de realistas fieles de Toluca, acusado de deserción", Criminal, vol. 522, exp. 12, fs. 408-414.

AGN (Archivo General de la Nación) (1819), "Sumaria instruida en Toluca a los tenientes Manuel Murillo y Bernardo Toral, sospechosos de haberse pasado a las fuerzas rebeldes de Iturbide: fueron absueltos y continuaron en el servicio, pero Toral sufrió dos meses de arresto", Criminal, vol. 143, exp. 3, 18 fs.

AGN (Archivo General de la Nación) (1819), "Francisco Salamanca, Gertrudis Espinoza, Mariano Espinoza Marcelino Vega, Joaquín de la Llera, Mariano Garduño, Mariano Farfán, Antonio Ordoñez, Juan Domingo y el presbítero Joaquín Omaña, estando presos desde 1810 solicitaron su libertad, pues fueron acusados de sedición en la época de la insurgencia, porque formaron parte de la Conspiración criolla de Toluca en ese año", Criminal, vol. 217, exp. 17, fs. 249-270.

AGN (Archivo General de la Nación) (1821), "En 1821 el ahora sargento coronel Nicolás Gutiérrez tuvo problemas por el rango con Francisco de Aranda, teniente coronel", Criminal, vol. 531, exp. 16, fs. 224-240.

AHMT (Archivo Histórico Municipal de Toluca), Actas de Cabildo, 5 de marzo de 1814.

AHMT (Archivo Histórico Municipal de Toluca), Actas de Cabildo, 9 de marzo de 1814.

AHMT (Archivo Histórico Municipal de Toluca), Actas de Cabildo, libro de 18141823, 9 de julio de 1814.
AHMT (Archivo Histórico Municipal de Toluca) (1814), Actas de Cabildo, libro de 1814-1823, 17 de diciembre.

AHMT (Archivo Histórico Municipal de Toluca) (1820), Actas de Cabildo, 29 de agosto.

AHMT (Archivo Histórico Municipal de Toluca) (1821), Actas de Cabildo, 9, 16, 23 y 30 de enero; 6 y 27 de febrero.

AHMT (Archivo Histórico Municipal de Toluca) (1821), Actas de Cabildo, 27 de marzo.

AHMT (Archivo Histórico Municipal de Toluca), Actas de Cabildo, alistando a los ciudadanos para defender la ciudad, 27 de marzo; necesidad de dinero para las obras de fortificación del Carmen, Beaterio, Cóporo y Calvario, que se están construyendo por disposición del comandante general de la plaza (Toluca), coronel Don Ángel Díaz del Castillo, 28 de mayo. En cabildo se informa sobre los gastos necesarios para hacer las fortificaciones de parapetos, cortaduras y reductos en la ciudad, 5 de junio de 1821.

Archivo Parroquial de El Sagrario (18051815), "Entierros de indios mexicanos", Toluca, Libro 7, 1809-1813, Caja 5, Defunciones, 1805-1815/ vol. 4, caja 77.

\section{Referencias}

Alanís Boyso, José Luis (1976), "Corregimiento de Toluca y elecciones de república en el siglo XVII", Historia Mexicana, 25 (3), Ciudad de México, El Colegio de México, pp. 455-477.

Arriaga Rivera, Armando (2017), "El urbanismo en los pueblos novohispanos: Tlaxcala y Toluca, 1519-1821", tesis de doctorado en historia, Universidad Autónoma del Estado de México-Facultad de Humanidades, Toluca.

Auñamendi Eusko Entziklopedia (s.f.), "Angulo Guardamino, Lorenzo", Eusko Ikaskuntza, <https://n9.cl/b8yo>, 13 de abril de 2021.

Barry Lawrence Ruderman Antique Maps 
Inc. (1817), "Plano de la ciudad de Toluca levantado de orden superior por el teniente agregado al Cuerpo de Ingenieros, José Mariano Domínguez de Mendoza", La Jolla, <https://bit.ly/3ncz1Uh>, 15 de agosto de 2021.

Bayardo Rodríguez, Lilia Esthela; Luna Pérez, Alba María y Mota Palmas, Karina del Rocío (2018), "Toluca, sus pueblos y haciendas en 1791. Un acercamiento a su estructura social", en María Teresa Jarquín y Manuel Miño (coords.), Toluca, los ejes históricos de una ciudad mexicana, Zinacantepec, El Colegio Mexiquense, A.C., pp. 51-94.

Beligand, Nadine (2017), Entre lagunas y volcanes. Una historia del Valle de Toluca (fines del siglo XV-fines del siglo XVIII), tomo 1, Zamora, El Colegio de Michoacán-Centro de Estudios Mexicanos y Centroamericanos.

Beltrán Silva, Marisela (2018), "Economías de guerra y acciones militares en la Región de Toluca, 1810-1816", tesis de maestría en Humanidades, Universidad Autónoma del Estado de México-Facultad de Humanidades, Toluca.

Carmona Dávila, Doralicia (2021), "Fernando VII jura la Constitución de Cádiz", Memoria Política de México, Ciudad de México, Instituto Nacional de Estudios Políticos, A.C., <https://n9.cl/9ejpq>, 10 de abril de 2021.

Castañeda García, Rafael (2014), "Hacia una sociología fiscal. El tributo de la población de color libre de la Nueva España, 1770-1810", Fronteras de la Historia, 19 (1), enero-junio, Bogotá, Instituto Colombiano de Antropología e Historia, pp. 152-173.

De Mayoralgo y Lodo Conde de los Acevedos, José Miguel (2014), "Antecedentes de la emancipación: el Reino de Nueva España en el Registro de la Real Estampilla (1759-1798)", Ciudad de México, Universidad Nacional Autónoma de México-Instituto de Investigaciones Históricas, <https://n9.cl/4s40b>, 20 de junio de 2021.

De Pagés de Puig, Aniceto (s.f), Gran dic- cionario de la lengua castellana (autoridades), tomo 4, Barcelona, Fomento Comercial del Libro.

El Valle de Carranza (2017), "Lorenzo Angulo Guardamino", 5 de diciembre de 2017, Lanestosa, Asociación Cultural Historias de Lanestosa, <https://n9.cl/vri$v r>, 4$ de abril de 2021.

Fernández Delgado, Miguel Ángel (2012), El virrey Iturrigaray y el Ayuntamiento de México en 1808, Ciudad de México, Instituto Nacional de Estudios Históricos de las Revoluciones de México.

García Luna, Margarita y Victoria Moreno, Dionisio (2013), Conspiración insurgente en Toluca, en 1810, Toluca, Ayuntamiento de Toluca-Instituto Municipal de Cultura y Arte.

García Martínez, Bernardo (1969), El Marquesado del Valle. Tres siglos de régimen señorial en Nueva España, Ciudad de México, El Colegio de México.

Gazeta del Gobierno de México (1812), "Jura de la Constitución de Cádiz en Toluca", T. III, vol. 2, núm. 319, 26 de octubre, pp. 1215-1218, 1223-1226.

Gazeta del Gobierno de México (1814), "Informe del coronel Lorenzo Angulo Guardamino sobre la Jura del Rey Fernando VII en Toluca", pp. 726-729.

Gazeta del Gobierno de México (1815), "Acta de fidelidad, que, en cumplimiento de lo prevenido en los artículos 7 y 9 del Bando publicado el 24 de mayo último, celebró el Ayuntamiento de dicha ciudad [Toluca], cuyo testimonio ha dirigido al Exmo. Sr. Virrey", vol. 10, T. VI, núm. 759, 9 de junio, pp. 796-798.

Guedea Rincón Gallardo, Virginia (2002), "La organización militar", en Woodrow Borah (coord.), El gobierno provincial en la Nueva España 1570-1787, Ciudad de México, Universidad Nacional Autónoma de México-Instituto de Investigaciones Históricas, pp. 125-148.

Gutiérrez Rubín de Celis, Francisco (1821), 
"Poesías que se presentaron en la vistosa Portería del Convento parroquial de Nuestro padre San Francisco de Toluca en los tres días de la Jura de nuestra deseada Independencia, que fueron 12, 13, y 14 de mayo de 1821", Mexicana, Repositorio del Patrimonio Cultural de México, Gobierno de México, <https:// n9.cl/x2072>, 23 de mayo de 2021.

Guzmán Pérez, Moisés (2014), "El Movimiento Trigarante y el fin de la guerra en Nueva España (1821)", Anuario Colombiano de Historia Social y de la Cultura, Bogotá, Universidad Nacional de Colombia-Departamento de Historia-Facultad de Ciencias Humanas, pp. 131-161.

Herrejón Peredo, Carlos (2007), La Diputación Provincial de la Nueva España. Actas de sesiones 1820-1821, tomo I, Zinacantepec, El Colegio Mexiquense/ Instituto de Investigaciones Jurídicas Dr. José María Luis Mora/El Colegio de Michoacán.

Ibarra Romero, Antonio (1995), "De los delitos políticos y la vida privada: los infidentes novohispanos 1809-1815 (Escenas cotidianas de obediencia y disidencia)", Anuario de Estudios Americanos, LII (2), Sevilla, Escuela de Estudios Hispano-Americanos, pp. 99-120, <https://bit.ly/3tULeOU>, 12 de junio de 2021.

Iracheta Cenecorta, María del Pilar y Martínez García, Raymundo (2002), "Una crónica de la guerra de independencia en el Valle de Toluca", Contribuciones desde Coatepec, núm. 3, Toluca, Universidad Autónoma del Estado de México-Facultad de Humanidades, pp. 68-87.

Javier López, Elisa (2017), "Tifo y mortalidad comparada: la epidemia de 1813 y la endemia de 1822-1824. Parroquia de San José de Toluca", en José Gustavo González Flores (coord.), Epidemias de matlazahuatl, tabardillo y tifo en Nueva España y México. Sobremortalidades con incidencia en la población adulta del siglo XVII al XIX, Saltillo, Universidad Autónoma de Coahuila-Escuela de Ciencias Sociales, pp. 123-141.
Jiménez Codinach, Guadalupe (2014), "El Imperio de Agustín de Iturbide", conferencia dictada en el Colegio del Estado de Hidalgo, 17 de octubre, Canal del Colegio del Estado de Hidalgo, <https:// bit.ly/3E1LHmP>, 22 de agosto de 2021.

Landavazo, Marco Antonio (2008), "Guerra y violencia durante la revolución de Independencia de México", Tzintzun. Revista de Estudios Históricos, núm. 48, Morelia, Universidad Michoacana de San Nicolás de Hidalgo, pp. 15-40, <https://bit.ly/317m8bf>, 10 de mayo de 2021.

León García, María del Carmen (2002), "El camino México-Toluca. Proyecto del ingeniero militar Manuel Agustín Mascaró. Nueva España, 1791-1795", Scripta Nova. Revista electrónica de Geografía y Ciencias Sociales, VI (123), Barcelona, pp. 105-132, <https://n9.cl/9oOet>, 4 de marzo de 2021.

López Ponce, Norberto (2017), "Los mártires de Toluca. 19 de octubre de 1811", La Co/mena, núm. 34, Toluca, Universidad Autónoma del Estado de México, pp. 96-103.

Mairot, Mark (2013), "Mexican provincial society during the age of Revolution: a social and economic history of Toluca, 1790-1834", tesis de doctorado, Universidad de California, Los Ángeles.

Martínez Borrallo, Antonio (2017), "Comerciantes vascos en los cinco gremios mayores de Madrid", Magallánica, Revista de Historia Moderna, 4 (7), julio-diciembre, Mar del Plata, Grupo de Investigación en Historia de Europa Moderna de la Facultad de Humanidades de la Universidad Nacional de Mar del Plata y por la Red de Historia Moderna, pp. 145-179.

Mejía Torres, Karen (2020), "Justicia y orden social en Toluca: un régimen corporativo en la integración urbana, 1669-1799", tesis de doctorado en Historia, El Colegio de México, Ciudad de México.

Mínguez Cornelles, Víctor (2007), "La ceremonia de Jura en la Nueva España: 
proclamaciones fernandinas en 1747 y 1808", Varia Historia, 23 (38), Belo Horizonte, pp. 273-292, <https://n9.cl/ uajt4>, 7 de marzo de 2021.

Moreno Gutiérrez, Rodrigo (2018), "La Restauración en la Nueva España: Guerra, cambios de régimen y militarización entre 1814 y 1820", Revista Universitaria de Historia Militar, 7 (15), Teruel, Centro de Estudios de la Guerra, pp. 101-125, <https://bit.ly/3heFJ8k>, 20 de abril de 2021.

Moreno Gutiérrez, Rodrigo (2014), "Las fuerzas armadas en la consumación de la Independencia. Nueva España 18201821", tesis de doctorado en Historia, El Colegio de México, Ciudad de México.

Moreno Romero, Juan Humberto (2012), "Iturbide: de la divinidad al oprobio", Horizonte Histórico, (5) 28-39, Aguascalientes, Universidad Autónoma de Aguascalientes, pp.1-12, <https://n9.cl/ gok3f, 15 de abril de 2020.

MVT (2012), "Una conspiración insurgente en Toluca, 1810", 14 de septiembre, Agencia de Noticias MVT, <https://bit. |y/3DZUsOJ>, 20 de marzo de 2021.

Ortiz Escamilla, Juan (2002) "De la sublevación clerical al autoritarismo militar: o de cómo el clero perdió sus privilegios durante la guerra civil de 1810", en Marta Terán y José Antonio Serrano (coords.), Las guerras de Independencia en la América Española, Zamora, El Colegio de Michoacán/Instituto Nacional de Antropología e Historia, pp. 205-216.

Ortiz Escamilla, Juan (2000), "La ciudad amenazada, el control social y la autocrítica del poder. La guerra civil de 1810-1821", Relaciones. Estudios de Historia y Sociedad, 21 (84), Zamora, El Colegio de Michoacán, A.C., pp. 17-57.

Pacheco Chávez, María Antonieta lluhí (2004), "La hacienda pública de los ayuntamientos en una etapa de transición política, 1786-1830. El caso del Estado de México", tesis de maestría en Ciencias Sociales con especialidad en
Desarrollo Municipal, El Colegio Mexiquense, A.C., Zinacantepec.

Peñaloza García, Inocente (2011), "Holocausto en la Plaza Mayor", en Alexander Naime (coord.), Los mártires de Toluca, Toluca, Universidad Autónoma del Estado de México, pp. 30-45.

Pérez Hernández, Rodrigo (2017), "El gobierno de los subdelegados en la intendencia de México. La formación de un ámbito de autoridad distrital en el sistema de intendencias novohispano, 1786-1810", tesis de doctorado en Historia, El Colegio de México, Ciudad de México.

Pérez Silva, Gerardo (2021a), "Proceso en contra de Alejo de la Cruz, Rufino Sevario y otros acusados de insurgentes", Facebook, <https://n9.cl/n5rlx>, 15 de abril de 2021.

Pérez Silva, Gerardo (2021b), "Informe del cura ministro de Toluca, fray Francisco Gómez al Provisor y Capitular sobre un inminente ataque al pueblo de Tlacotepec", Facebook, <https://n9.cl/n5rlx>, 15 de abril de 2021.

Quintana Roo, Andrés (1820), "La libertad y la tiranía. Composición alegórica en celebridad del juramento de la Constitución política de la Monarquía Española solemnizado en la ciudad de Toluca a 11 de junio de 1820", México, Imprenta de D. Juan Bautista de Arizpe, <https://sas-space.sas.ac.uk/7588/>, 27 de mayo de 2021.

RAE (Real Academia Española) (1976), Diccionario de Autoridades de la Lengua Española, Editorial Gredos, Madrid.

Romero, José Luis (1984), Latinoamérica, las ciudades y las ideas, Ciudad de México, Siglo XXI.

Romero Quiroz, Javier (1973), La ciudad de Toluca, su historia, tomo II, Toluca, Gobierno del Estado de México.

Sánchez Montiel, Juan Carlos (2009), "Formación de ayuntamientos constitucio- 
nales y un nuevo sistema de representación política en los pueblos-misión de Rioverde, San Luis Potosí, 1812-1826", Estudios de historia moderna y contemporánea de México, núm. 37, Ciudad de México, Universidad Nacional Autónoma de México, pp. 37-69, <https://bit. ly/3zY9th2>, 13 de abril de 2020.

Sánchez Uriarte, María del Carmen (1997), "Las fiebres misteriosas del año 1813 y la guerra de Independencia", tesis de licenciatura en Historia, Universidad Iberoamericana, Ciudad de México.

Santos Villarreal, Gabriel (2010), "Religión y política. Sacerdotes en la Independencia de México", Ciudad de México, Cámara de Diputados-Dirección general de servicios de Documentación, Información y Análisis, <https://n9. $\mathrm{cl} / 2 \mathrm{kxy}>, 2$ de abril de 2021.

Villalpando César, José Manuel (2002), "En el Monte de las Cruces", en Miguel Hidalgo, México, Planeta DeAgostini.

Von Wobeser, Gisela (2018), "El gobierno en el Marquesado del Valle de Oaxaca", Históricas Digital, Ciudad de México, Universidad Nacional Autónoma de México, pp. 183-206, <https://bit. Iy/3tuGILX>, 20 de julio de 2021.

Yurrieta Valdés, José (2014), Un insurgente desconocido: Fray Luis Gonzaga Oronoz, Toluca, Universidad Autónoma del Estado de México.

Recibido: 14 de mayo de 2021. Reenviado: 17 de mayo de 2021. Aceptado: 16 de agosto de 2021.

\section{María del Pilar Iracheta Cenecorta}

Doctora en Historia por la Universidad Autónoma de Zacatecas "Francisco García Salinas". Desde 1994 se desempeña como Profesora-Investigadora de El Colegio Mexiquense, A.C. Es miembro del Sistema Nacional de Investigadores, nivel I. Sus líneas de investigación actuales son: Recursos Naturales (agua), Historia Política y Sociocultural del Municipio. Entre sus más recientes publicaciones destacan, como coautora: "Los trabajadores toluqueños según el Censo de 1849", en María Teresa Jarquín Ortega y Manuel Miño (coords.),Toluca. Los ejes históricos de una ciudad mexicana, Zinacantepec, El Colegio Mexiquense, A.C., pp. 159-214 (2018); "Entre santos y fiestas. Una aproximación a la religiosidad de San Mateo Atenco en los siglos XVII y XVIII", en San Mateo Atenco, Cuaderno Municipal, núm. 27; cocoordinadora de Atlacomulco, Cuaderno núm. 28, Zinacantepec, El Colegio Mexiquense, A.C. (próximamente). Como autora: Capítulo IV, "Del periodo independentista a las Leyes de Reforma (1821-1856)"; Capítulo $V$, "De las guerras de Reforma e Intervención Francesa a la República Restaurada (1857-1876)"; Capítulo VI, "El Porfiriato"; Capítulo VII, "De la Revolución a la década de 1940”, en Yoko Sugiura Yamamoto, José Antonio Álvarez Lobato y Elizabeth Zepeda Valverde (coords.), La cuenca del Alto Lerma: ayer y hoy. Su historia y su etnografía, Zinacantepec, El Colegio Mexiquense, A.C./ Gobierno del Estado de México, pp. 167-206 y 231-250 (2016); En busca de la Pompeya Mexicana. Las exploraciones de Leopoldo Batres en Teotihuacan, Toluca, 1905-1910, Zinacantepec, El Colegio Mexiquense, A.C./ Gobierno del Estado de México/Universidad Autónoma del Estado de México (2016). 
